\title{
$\alpha-1$ Antitrypsin regulates human neutrophil chemotaxis induced by soluble immune complexes and IL-8
}

\author{
David A. Bergin, ${ }^{1}$ Emer P. Reeves, ${ }^{1}$ Paula Meleady, ${ }^{2}$ Michael Henry, ${ }^{2}$ \\ Oliver J. McElvaney, ${ }^{1}$ Tomás P. Carroll, ${ }^{1}$ Claire Condron, ${ }^{1}$ Sanjay H. Chotirmall, ${ }^{1}$ \\ Martin Clynes, ${ }^{2}$ Shane J. O'Neill, ${ }^{1}$ and Noel G. McElvaney' \\ ${ }^{1}$ Respiratory Research Division, Department of Medicine, Royal College of Surgeons in Ireland, Education and Research Centre, \\ Beaumont Hospital, Dublin, Ireland. ${ }^{2}$ National Institute for Cellular Biotechnology, Dublin City University, Dublin, Ireland.
}

\begin{abstract}
Hereditary deficiency of the protein $\alpha-1$ antitrypsin (AAT) causes a chronic lung disease in humans that is characterized by excessive mobilization of neutrophils into the lung. However, the reason for the increased neutrophil burden has not been fully elucidated. In this study we have demonstrated using human neutrophils that serum AAT coordinates both CXCR1- and soluble immune complex (sIC) receptor-mediated chemotaxis by divergent pathways. We demonstrated that glycosylated AAT can bind to IL-8 (a ligand for CXCR1) and that AAT-IL-8 complex formation prevented IL-8 interaction with CXCR1. Second, AAT modulated neutrophil chemotaxis in response to sIC by controlling membrane expression of the glycosylphosphatidylinositolanchored (GPI-anchored) Fc receptor Fc $\gamma$ RIIIb. This process was mediated through inhibition of ADAM-17 enzymatic activity. Neutrophils isolated from clinically stable AAT-deficient patients were characterized by low membrane expression of Fc $\gamma \mathrm{RIIIb}$ and increased chemotaxis in response to IL-8 and sIC. Treatment of AATdeficient individuals with AAT augmentation therapy resulted in increased AAT binding to IL-8, increased AAT binding to the neutrophil membrane, decreased Fc $\gamma$ RIIIb release from the neutrophil membrane, and normalization of chemotaxis. These results provide new insight into the mechanism underlying the effect of AAT augmentation therapy in the pulmonary disease associated with AAT deficiency.
\end{abstract}

\section{Introduction}

$\alpha-1$ Antitrypsin (AAT), a 52-kDa glycosylated protein primarily synthesized in the liver, is the major physiological inhibitor of a range of serine proteases, and within the lung maintains a protease-antiprotease balance. Recent studies indicate that AAT also possesses antiinflammatory capabilities that extend beyond its antiprotease role, including regulation of CD14 expression (1), inhibition of TNF- $\alpha$ gene upregulation (2), and inhibition of lipopolysaccharide activation of human monocytes and neutrophil migration in vitro $(3,4)$. In addition, AAT has been shown to downregulate apoptosis (5) and to inhibit antiproteinase 3 antibody activation of neutrophils (6).

Studying the function of AAT is facilitated by the existence of an in vivo model, namely AAT deficiency (AATD). This hereditary condition provides us with the most definitive evidence for the physiological and clinical importance of AAT. AATD is a syndrome, the unifying features of which are a predisposition to emphysema, liver disease, and skin panniculitis. The liver disease associated with AATD involves a gain-of-function mutation (PiZZ) that results in accumulation of polymers of Z-AAT within rough endoplasmic reticulum, leading to activation of ER stress responses (7-9). Pathogenesis of AATD-associated skin panniculitis is largely undefined, and most active research to date has focused on the pulmonary manifestations of the disease. In the past, the protease-antiprotease imbalance theory was accepted as a reason for the pulmonary emphysema associated with AATD. Studies focused upon the role

Authorship note: David A. Bergin and Emer P. Reeves contributed equally to this work.

Conflict of interest: The authors have declared that no conflict of interest exists. Citation for this article: J Clin Invest. 2010;120(12):4236-4250. doi:10.1172/JCI41196. of proteases as a primary contributor to lung tissue damage $(10,11)$, and the protease-antiprotease hypothesis was consolidated further, as AAT augmentation therapy reversed the biochemical abnormalities in lung fluid and impacted on proteolytic activity (12).

Evidence exists that the neutrophil is the main source of the proteolytic burden within the AATD lung, and airway neutrophilic inflammation plays a major role in the pathogenesis of AATDassociated emphysema. An increased lung neutrophil burden has been described even in AATD subjects with mild functional lung impairment (13) and also in asymptomatic nonsmoking heterozygotes for the $\mathrm{Z}$ allele or intermediate deficiency (PiMZ) without airflow obstruction (14). However, the reason for the observed increased neutrophil burden has never been fully elucidated, and with the aim of clarifying the important role of AAT in chronic neutrophilic infiltration, we investigated whether dysregulated neutrophil chemotaxis is associated with changes in neutrophil properties of AATD individuals.

Our results show an inhibitory effect of AAT on neutrophil chemotaxis and illustrate that a low-AAT environment, such as that occurring in the circulation of ZZ-AATD individuals (3-7 $\mu \mathrm{mol} / 1$ compared with normal plasma levels of $20-50 \mu \mathrm{mol} / 1)$, correlates with increased chemotactic responses of both CXCR1 and immune complex receptor (Fcy RIIIb) signaling. We demonstrate that neutrophil chemotaxis is dependent on opposing gradient concentrations of both IL-8 and AAT and that AAT-IL-8 complex formation inhibits CXCR1 engagement. We further show that AAT is associated with neutrophil membrane lipid rafts, interacting with the glycosylphosphatidylinositol-linked (GPI-linked) membrane protein FcyRIIIb. We demonstrate that AAT can control immune complex-mediated neutrophil chemotaxis by inhibiting ADAM-17 

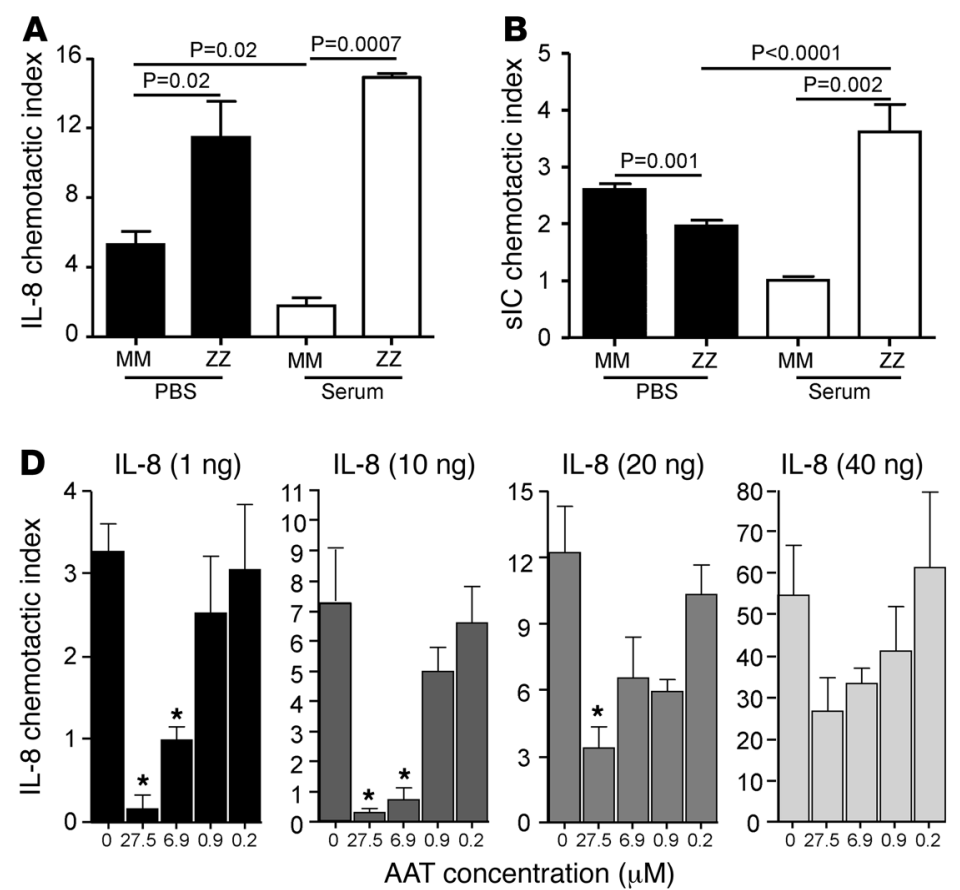
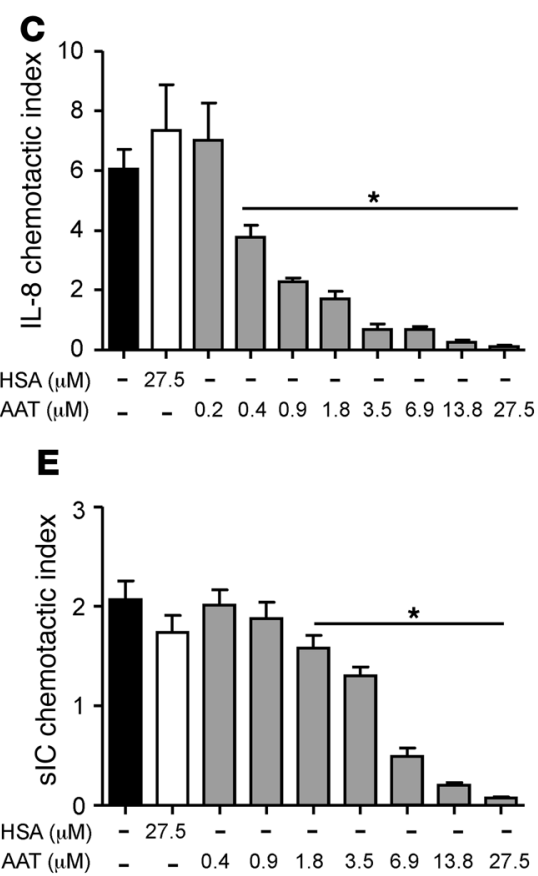

\section{Figure 1}

Chemotactic analysis of neutrophils in response to AAT. (A) Increased mean chemotactic index of ZZ-AATD neutrophils $(n=6)$ compared with healthy control (MM) cells $(n=6)$ in response to IL-8 $\left(10 \mathrm{ng} / 2 \times 10^{7}\right.$ cells). Assays were preformed in PBS or serum $(50 \% \mathrm{v} / \mathrm{v})$ from respective ZZ or MM individuals. (B) Decreased mean chemotactic index of ZZ-AATD neutrophils $(n=6)$ in PBS in response to sIC (10\% v/v), yet increased mean chemotactic index of ZZ-AATD neutrophils in serum $(50 \% \mathrm{v} / \mathrm{v})$ compared with healthy control cells $(n=6)$. (C) An increase in chemotactic inhibition efficiency of increasing concentration of AAT $(0.2-27.5 \mu \mathrm{M})$. Black bar, positive IL-8 $(10 \mathrm{ng})$ control; white bar, negative HSA (27.5 $\mu \mathrm{M})$ control. ${ }^{*} P<0.05$ versus IL-8 control. (D) Neutrophil chemotaxis in a linear gradient of IL-8 $(1,10,20$, or 40 ng) or complex gradient in the presence of inhibitory AAT $(27.5,6.9,0.9,0.2 \mu \mathrm{M})\left({ }^{*} P<0.05\right.$ compared with AAT-untreated cells). (E) Increased chemotactic inhibition efficiency of increasing concentrations of AAT $(0.4-27.5 \mu \mathrm{M})$. Black bar, positive sIC $(10 \% \mathrm{v} / \mathrm{v})$ control; white bar, negative HSA $(27.5 \mu \mathrm{M})$ control. ${ }^{*} P<0.05$ versus sIC control. Experiments illustrated in A-E were performed in triplicate on 3 consecutive days, and for comparative analysis the PBS control was set at a chemotactic index of 1 . Each measurement is the mean \pm SEM.

(TACE) activity and preventing the release of FcyRIIIb from the cell. This AAT-induced modulatory effect was also observed in vivo, in AATD individuals receiving augmentation therapy. After infusion, increased serum levels of AAT bound IL-8- and FC $\gamma$ RIIIb-expressing neutrophils and normalized AATD neutrophil chemotactic responses. This study provides a mechanism for the pathway by which AAT may mediate its antiinflammatory effect upon the circulating neutrophil and expands our understanding of the role of AAT in health and disease.

\section{Results}

$A A T$ activity regulates $I L-8$ and immune complex-induced neutrophil chemotaxis. The chemotactic index of ZZ neutrophils obtained from 6 clinically stable AATD individuals was compared with that of control neutrophils (MM) from 6 healthy donors. Results revealed that in response to IL-8 (10 ng), ZZ neutrophils exhibited a 2- or 8 -fold increase in chemotactic activity when experiments were performed in PBS or serum $(50 \% \mathrm{v} / \mathrm{v})$, respectively (Figure $1 \mathrm{~A})$. In addition, in response to IL- 8 the chemotactic index of MM neutrophils suspended in PBS was superior to that of MM cells suspended in serum $(P=0.02)$. Moreover, the chemotactic index of $\mathrm{ZZ}$ neutrophils in response to soluble immune complex (sIC) $(10 \% \mathrm{v} / \mathrm{v})$ was $25 \%$ lower than that of MM control cells when performed in PBS $(P=0.001)$, yet 3.6-fold higher when experiments were repeated in the presence of respective $\mathrm{ZZ}$ and MM sera (Figure 1B).
To investigate whether the increased chemotactic activity of $\mathrm{ZZ}$ neutrophils in response to IL- 8 was a result of AATD, we explored the effect of exogenous AAT on neutrophil chemotaxis. As illustrated in Figure $1 \mathrm{C}$, the chemotactic index of MM neutrophils in response to IL-8 (10 ng) was $6.05 \pm 0.66$. AAT inhibited MM neutrophil chemotaxis in a dose-dependent manner, with an $\mathrm{IC}_{50}$ of $0.5 \mu \mathrm{M}$. HSA (control plasma protein, $27.5 \mu \mathrm{M}$ ) did not affect neutrophil chemotaxis. At a higher concentration, AAT $(6.9 \mu \mathrm{M})$ reduced the MM neutrophil chemotactic index produced by $10 \mathrm{ng}$ or $20 \mathrm{ng}$ IL- 8 by $91.5 \%$ $(P=0.002)$ and $46.8 \%(P=0.07)$, respectively (Figure 1D). Biologically relevant serum concentrations of AAT $(27.5 \mu \mathrm{M})$ abolished neutrophil chemotaxis in response to $1 \mathrm{ng}$ or $10 \mathrm{ng}$ IL- 8 and reduced the cellular chemotaxis index to $20 \mathrm{ng}$ and $40 \mathrm{ng}$ IL- 8 by approximately $72 \%$ and $52 \%(P=0.009$ and $P=0.09$, respectively). To investigate the inhibitory effect of AAT on IL-8's chemotactic activity (versus chemokinesis), we also used checkerboard analysis with serial dilutions of IL- 8 above and below the filter. Neutrophil migration depended on the presence of an IL-8 gradient, implying that AAT inhibits directed cell migration rather than chemokinesis (Supplemental Figure 1, A and B; supplemental material available online with this article; doi:10.1172/JCI41196DS1). The effect of exogenous AAT $(0.4-27.5 \mu \mathrm{M})$ on the chemotactic index of MM neutrophils in response to sIC $(10 \% \mathrm{v} / \mathrm{v})$ was explored next. As illustrated in Figure 1E, AAT inhibited MM neutrophil chemotaxis in a dose-dependent manner, with an $\mathrm{IC}_{50}$ of $8.2 \mu \mathrm{M}$, while $\mathrm{HSA}(27.5 \mu \mathrm{M})$ had no effect on sIC-mediated chemotaxis. 


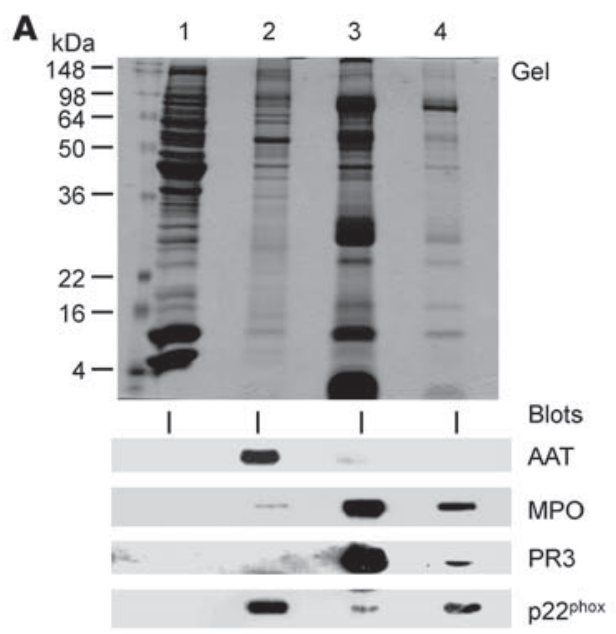

$\mathbf{E}$

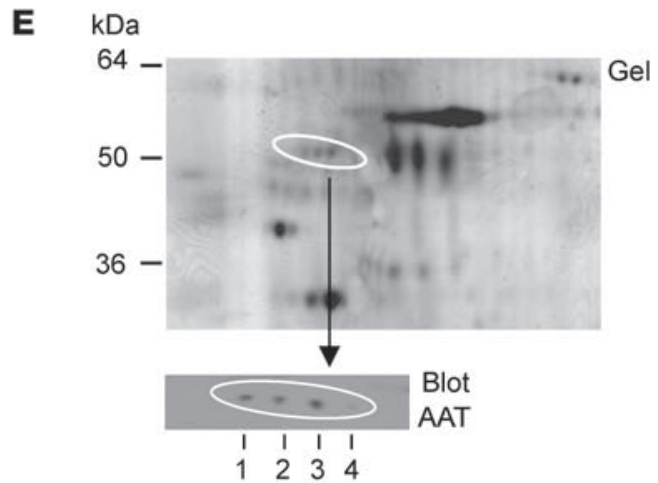

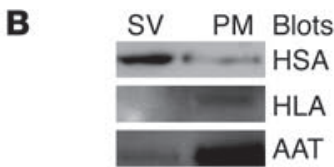

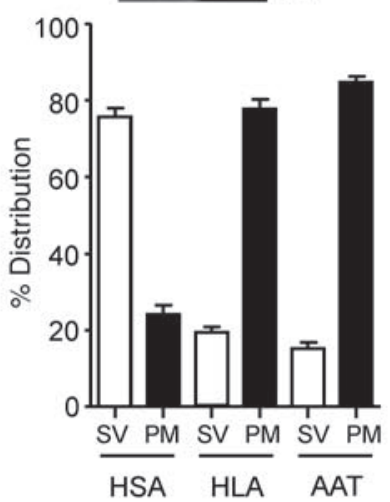

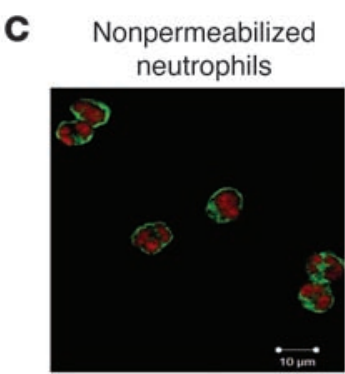

D

$1415(\%$ w/w sucrose $)$

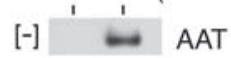

$[+]$

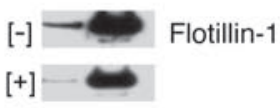

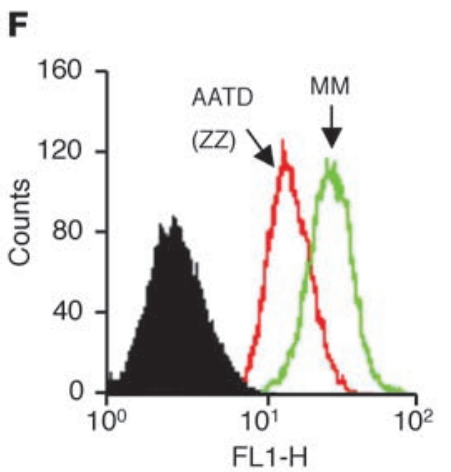

Figure 2

Localization of AAT in peripheral blood neutrophils. (A) Coomassie blue-stained gel of normal MM neutrophils subjected to subcellular fractionation yielding a cytosol fraction (lane 1), combined secretory vesicle/plasma membrane fraction (lane 2), and primary and secondary granule fraction (lanes 3 and 4, respectively). Western blotting employed antibodies to MPO and PR3 as markers of primary granules and antibodies against p2 $^{\text {phox }}$ of cytochrome $b_{558}$ as a marker of secondary granules and combined secretory vesicle/membrane fractions. AAT was localized to the secretory vesicle/membrane fraction at the interface between the $17.5 / 35 \%(\mathrm{w} / \mathrm{w})$ sucrose. (B) By Percoll gradient fractionation, approximately $83 \%$ of AAT was localized to the plasma membrane (PM) compared with secretory vesicles (SV). As controls, HLA served as a marker of PM and HSA as a marker of SV. (C) By confocal microscopy, the distribution of AAT in non-permeabilized MM neutrophils was predominantly localized to the membrane margin of the cell. Cell nuclei are stained red. Scale bar: $10 \mu \mathrm{m}$. (D) Detection of AAT and flotillin-1 in the low-density lipid raft fractions ( $15 \% \mathrm{w} / \mathrm{w}$ sucrose) of human MM neutrophil lysates: untreated (-) or treated with M $\beta C D(10 \mathrm{mM})(+)$. Immunoblots were probed with polyclonal anti-AAT and monoclonal anti-flotillin-1. (E) Coomassie blue-stained 2D SDS-PAGE gel of isolated MM neutrophil membrane lipid rafts (top panel). A Western blot probed with polyclonal anti-AAT revealed 4 associated AAT isoforms (lower panel). (F) Flow cytometry analysis of membrane-bound AAT in isolated resting MM (green) and ZZ-AATD (red) neutrophils. The level of AAT was found to be significantly higher on resting MM neutrophils. The isotype control antibody is illustrated in black (filled). Experiments in $\mathbf{A}, \mathbf{D}$, and $\mathbf{E}$ are each representative gels and blots of 3 separate experiments. Results in B represent experiments performed in triplicate on 3 consecutive days, and each bar is the mean \pm SEM. Confocal analysis in $\mathbf{C}$ and FACS analysis in F are one illustrative result from 3 independent experiments.

To understand (a) how AAT inhibited both IL-8 and sIC mediated MM neutrophil chemotaxis, (b) why ZZ cells demonstrated an increased chemotactic response to IL-8, and (c) why ZZ neutrophils illustrated conflicting chemotactic responses to sIC in PBS and serum was the goal of subsequent experiments.

AAT is localized to the neutrophil membrane. To establish how AAT impacted on neutrophil chemotaxis, it was necessary to pinpoint its location within the cell. By subcellular fractionation of neutrophils, AAT was defined as a component of the cell membrane (Figure 2A). Successful separation of plasma membranes from secretory vesicles was validated by Western blotting for HLA class I and HSA, and $83 \% \pm 1.5 \%$ of AAT was localized within the plasma membrane frac- tion (Figure 2B). Confocal laser scanning microscopy was employed to confirm localization of AAT to the membrane and showed bright foci of anti-AAT labeling in the membrane region of isolated cells (Figure 2C). In addition, AAT was found in association with detergent-free low-density sucrose fractions $(15 \% \mathrm{w} / \mathrm{w})$ containing membrane lipid rafts (Figure 2D). A similar distribution of flotillin-1 was observed, and treatment with the cholesterol-sequestering agent methyl- $\beta$-cyclodextrin $(\mathrm{M} \beta \mathrm{CD})$ diminished AAT and reduced the level of flotillin-1 in the low-density sucrose fractions. 2D electrophoresis of isolated MM neutrophil membranes (Supplemental Figure 2A) and purified membrane lipid rafts (Figure 2E) revealed 4 isoforms of AAT of similar molecular mass $(\sim 52 \mathrm{kDa})$. By employ- 
A
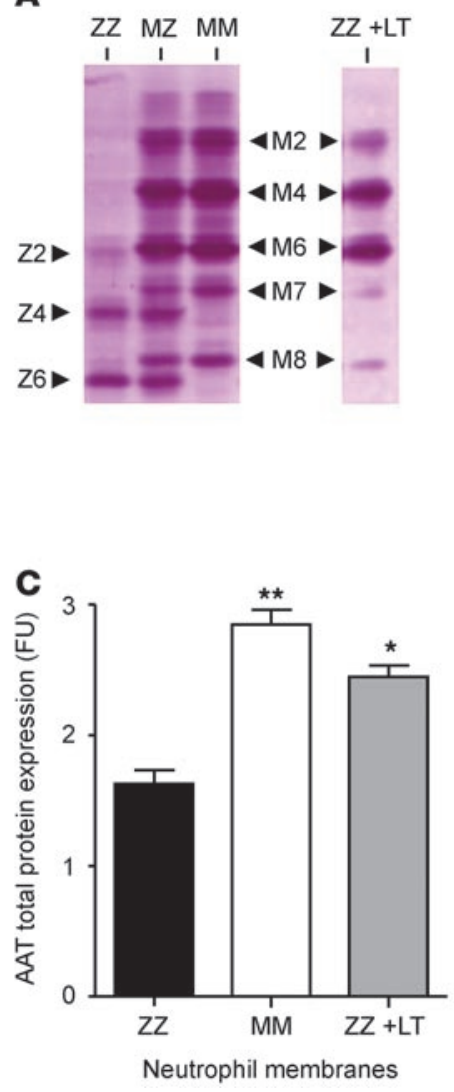

ing FACS analysis of nonpermeabilized cells, we detected AAT on the plasma membrane of unstimulated resting MM healthy neutrophils (Figure 2F). In contrast, neutrophils isolated from ZZ-AATD individuals illustrated significantly lower levels of AAT (mean fluorescence: control MM cells, 31.41; ZZ-AATD cells, 17.52; $P=0.001$ ). Fractionation of $\mathrm{ZZ}$ neutrophil cytosol, membrane, and granule compartments localized Z-AAT to neutrophil membranes, with reduced levels $(\sim 50 \%)$ confirmed by Western blotting (Supplemental Figure 2B). Collectively, these findings support localization of AAT to the neutrophil membrane and reveal that ZZ-AATD cells express significantly lower levels of AAT.

Origin of membrane-associated AAT. To clarify whether AAT was being produced by the neutrophil, as has been described by others (15), or whether it was being absorbed from the serum, we compared the phenotype of MM and ZZ-AATD neutrophil membrane-associated AAT with that of a ZZ-AATD individual after liver transplantation. Figure 3A shows the different patterns of phenotypes frequently observed for serum of MM and ZZ-AATD individuals (16). The phenotype of the ZZ-AATD serum sample after liver transplantation was entirely $M M$, a result confirmed by the use of an ELISA specific for the $\mathrm{ZZ}$ protein $(17,18)$ (Figure $3 \mathrm{~B}$ ). In contrast, neutrophil membranes of the ZZ-AATD liver transplant recipient contained detectable levels of Z-AAT protein (Figure 3B). Additionally, although these cells contained lower levels of membrane Z-AAT compared with a non-transplant patient, greater levels of total AAT ( $Z$ and $M$ isoforms) were detected by ELISA (Figure 3C) and immunoblotting (Figure 3D), most likely due to absorption of MM AAT from the serum. Collectively, these experiments suggest that both serum- and neutrophil-derived AAT binds the cell membrane.

\section{Figure 3}

Serum- and neutrophil-derived AAT binds the neutrophil membrane. (A) Isoelectrofocusing patterns for $Z Z$, heterozygous $M Z$, or MM serum compared with serum of a ZZ-AATD individual after liver transplantation $(Z Z+L T)$. The isoform numbers for the $M$ and $Z$ variants are indicated. The AAT pattern of the $Z Z+L T$ sample was of the M variant. (B) ELISA for detection of the Z-form of AAT in serum and neutrophil membranes. Results in arbitrary fluorescence units (FU) indicate positive detection of Z-AAT in serum and neutrophil membranes of a ZZ-AATD patient but only in neutrophil membranes after $\mathrm{LT}(P=0.2$ between $\mathrm{ZZ}$ and $\mathrm{ZZ}+\mathrm{LT}$ neutrophil membranes). An ELISA for detection of total AAT ( $M$ and $Z$ variants) $(C)$ and Western blots probed with goat (Gt) polyclonal anti-AAT (D) revealed significantly higher levels of total AAT on ZZ-AATD neutrophil membranes after liver transplantation (ZZ+LT) compared with a non-transplant ZZ-AATD patient $\left({ }^{\star} P=0.01,{ }^{\star \star} P=0.001\right)$. Results represent experiments performed in triplicate, and data in $\mathbf{B}$ and $\mathbf{C}$ are the mean \pm SEM.
Gt anti-AAT

$\beta$-actin

(loading control)
Proinflammatory cytokine exposure causes release of AAT within a protein complex. The effect of proinflammatory stimuli (IL-8 or TNF- $\alpha$ ) on release/shedding of AAT from the neutrophil membrane was investigated. MM neutrophils were treated with TNF- $\alpha$ (10 ng), a known potent inducer of L-selectin (CD62-L) shedding (Figure 4A). After 10 minutes of treatment, a significant decrease in cell surface AAT was detected by flow cytometry (mean fluorescence: control untreated cells, 20.7; TNF- $\alpha$-treated cells, 10.28; $P<0.001$ ) (Figure 4A). A corresponding increase in released AAT in the surrounding medium was detected by Western blot analysis, with a maximum increase in extracellular released AAT at $40 \mathrm{ng}$ TNF- $\alpha$ and $20 \mathrm{ng}$ IL-8 (Figure 4B). To assess the kinetics of shedding, we treated neutrophils with 10 ng IL- 8 or TNF- $\alpha$ and assessed extracellular released $\mathrm{AAT}$ at 2, 5, and 10 minutes. As depicted in Figure 4C, an immunoreactive band corresponding to released AAT was detected at 5 and 10 minute after TNF- $\alpha$ treatment and at an earlier time point of 2 minutes in response to IL-8. Maximum release of AAT from neutrophil membranes exposed to either IL- 8 or TNF- $\alpha$ occurred at 10 minutes (Supplemental Figure 3, A-D). ELISA was performed to quantify levels of released AAT, and at the 2-and 5-minute time points, neutrophils released $4.46 \pm 1.13$ and $5.25 \pm 0.44 \mathrm{ng}$ AAT per $1 \times 10^{7}$ neutrophils in response to IL-8 (10 ng) (Figure 4D). In contrast, and at the same time points, neutrophils released significantly lower levels of AAT in response to TNF- $\alpha$ treatment $(P=0.02$ and $P=0.014$ for 2 and 5 minutes, respectively). To investigate whether neutrophils synthesized AAT to substitute for membranereleased AAT, we exposed cells to IL-8 (10 ng) and quantified levels of extracellular and membrane-associated AAT for up to 16 hours. Results revealed no increase in either membrane-associated or 

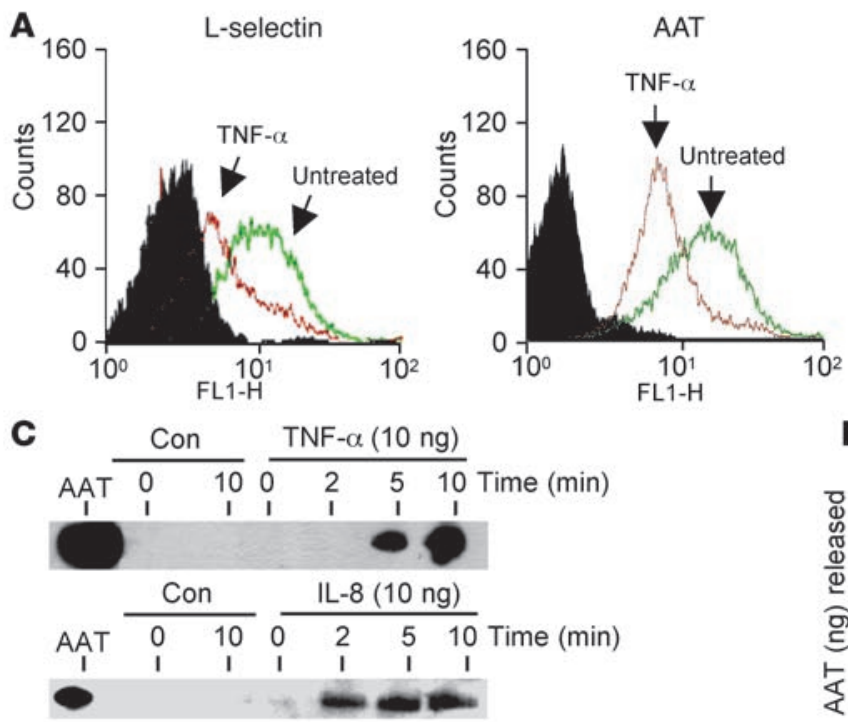

$\mathbf{E}$

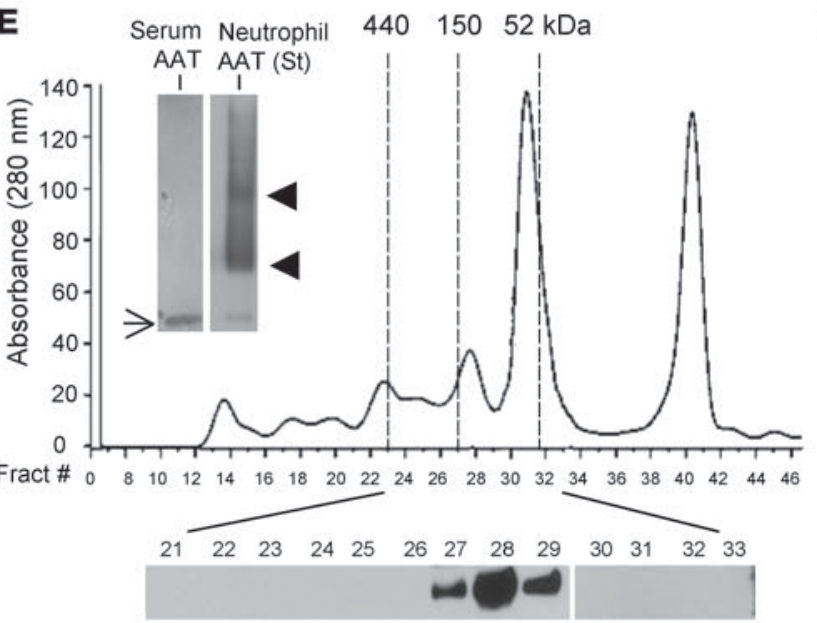

B

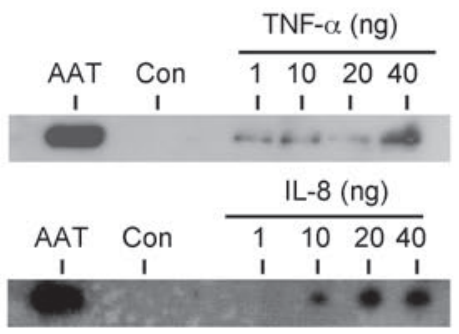

D

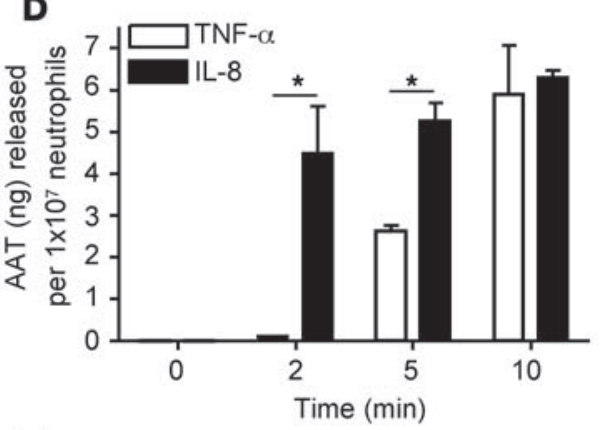

$\mathbf{F}$

\section{Figure 4}

Release of biologically active AAT from TNF- $\alpha$ - or IL-8-treated MM neutrophils. (A) Membrane expression of L-selectin or AAT on neutrophils at baseline (green) or in response to TNF- $\alpha$ (red). (B) Western blot showing extracellular released AAT (52 kDa) following treatment with TNF- $\alpha$ or IL-8 in a dose- (B) and time-dependent manner (C). Serum AAT (52 kDa) was loaded as a positive antibody control, and untreated cells are in lanes labeled as control (Con). (D) Time course analysis of the release of AAT $\left({ }^{\star} P<0.05\right)$. (E) Gel filtration chromatography of neutrophilreleased AAT. The start material (St) was released AAT from IL-8-treated neutrophils (10 ng). Inset: Western blot analysis illustrating altered migration of purified serum AAT (arrow) compared with neutrophil-released AAT (arrowheads). By Western blot analysis, fraction 28 contained neutrophil-released AAT and chromatographed at a molecular mass of 100-110 kDa. Fractions 30-33 were run on separate gels. (F) Formation of AAT-protease complexes. Samples were immunoblotted employing a rabbit anti-human AAT antibody. Lanes 1 and 3 show serum purified AAT and AAT released from neutrophils, respectively. Lanes 2 and 4 illustrate serum and neutrophil-released AAT incubated with NE. FACS analysis illustrated in $\mathbf{A}$ is a representative result of 3 independent experiments. B, C, and $\mathbf{F}$ are each representative Western blots of 3 separate experiments. Results in $\mathbf{D}$ represent experiments performed in triplicate. Each measurement is the mean \pm SEM. FPLC analyses (E) were performed in triplicate on 2 consecutive days.

newly released levels of AAT (Supplemental Figure 3E), suggesting that de novo protein synthesis of AAT did not occur.

Native gel electrophoresis was employed to examine potential conformational differences between serum purified AAT and IL-8induced neutrophil-released AAT. Serum AAT migrated faster and ran as a predominant single band (Figure 4E, inset). In contrast, neutrophil-released AAT migrated differently from serum AAT, showing a smeared, retarded mobility suggestive of a significant degree of conformational heterogeneity and/or protein-protein complexation. For assessment of the complexed state of the AAT species present, neutrophil-released AAT was chromatographed by gel filtration on a Superose 6 column. Protein elution was monitored by Western blot analysis, and as can be seen in Figure 4E, neutrophil AAT protein eluted at a position corresponding to a complex 

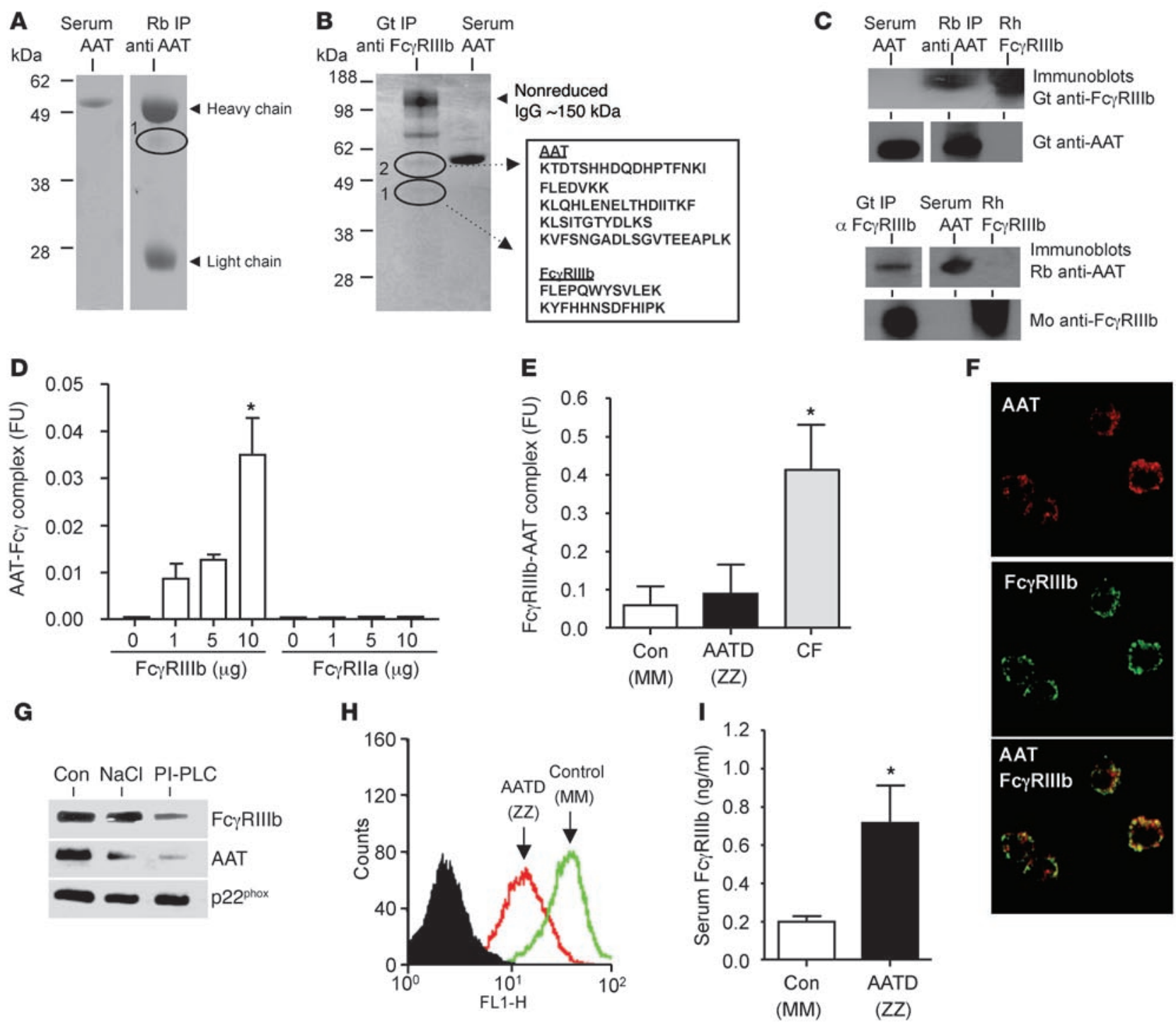

Figure 5

AAT binds Fc $\gamma$ RIIllb on the neutrophil membrane. (A) Immunoprecipitate (IP) employing rabbit (Rb) antibody to AAT. The AAT binding partner

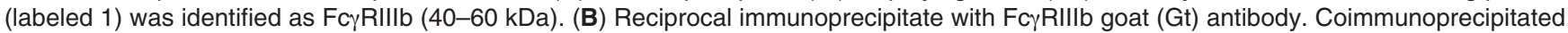
proteins were identified as Fc $\gamma$ RIIlb (labeled 1; accession number AA128563) and as AAT (labeled 2; accession number CAJ15161). (C) Western blots of immunoprecipitate reactions were performed with goat antibody against AAT (top panel) and mouse (Mo) antibody against FcyRIllb

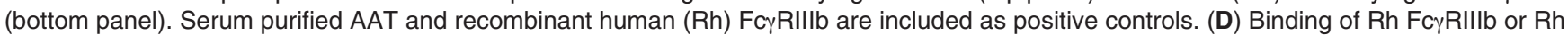

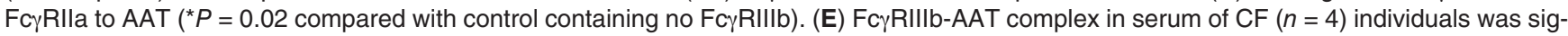
nificantly higher than that of normal MM (Con; $n=6)$ or AATD $(n=6)$ subjects $\left({ }^{*} P<0.05\right.$, CF versus control or ZZ). (F) Colocalization (merged image in yellow) of rhodamine labeling for AAT and FITC for FC $\gamma$ RIllb, at the membrane margin of cells ( $\times 64$ magnification, $\times 4$ zoom). (G) NaCl and PI-PLC treatment of neutrophil membranes. Immunoblots included untreated membranes (Con) and antibodies against p22 ${ }^{\text {phox }}$. (H) Flow cytometry analysis of membrane-bound FcyRIIlb (mean fluorescence: MM, 41.93; ZZ, 15.44). The isotype control antibody is in black (filled). (I) Levels of FcyRIIIb in serum of ZZ-AATD individuals and MM controls (Con) $\left({ }^{*} P=0.01\right)$. In $\mathbf{A}-\mathbf{C}$ and $\mathbf{G}$, images are representative results from 1 of 3 separate experiments. Lanes in $\mathbf{A}$ and $\mathbf{C}$ were run on the same gel but were noncontiguous. $\mathbf{D}, \mathbf{E}, \mathbf{H}$, and I represent results performed in triplicate. Images in $\mathbf{F}$ are representative results of 2 independent experiments.

molecular mass of approximately $100-110 \mathrm{kDa}$. To exclude the possibility that neutrophil-released AAT eluted at increased molecular mass due to a protease-inhibitor complex, we confirmed the affinity of neutrophil-released AAT for neutrophil elastase (Figure 4F).

AAT interacts with the neutrophil membrane via the GPI-anchored lipid raft membrane protein FcyRIIIb. AAT was immunoprecipitated from IL-8-induced neutrophil-shedded material by rabbit polyclonal
anti-AAT and the immunoprecipitates resolved by denaturing and reducing SDS-PAGE. A Coomassie blue stained gel is illustrated in Figure 5A, and a putative 45 - to $50-\mathrm{kDa}$ AAT binding partner

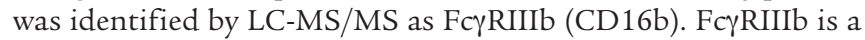
GPI-linked low-affinity IgG receptor, and to exclude the possibility of experimental binding artefact, we performed reciprocal immunoprecipitation of Fc $\gamma$ RIIIb and subsequent identification 
A

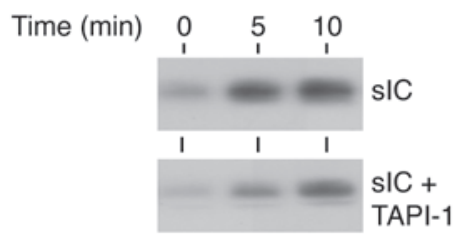

B

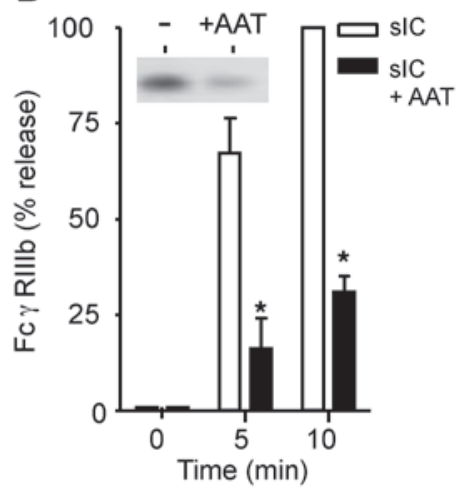

C

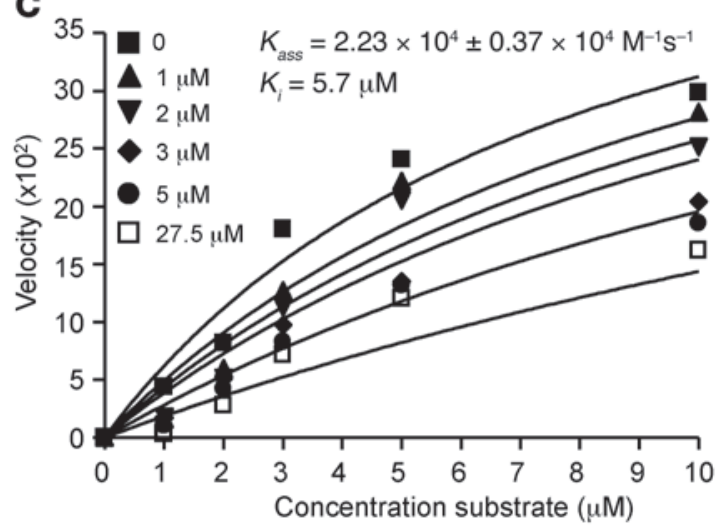

E

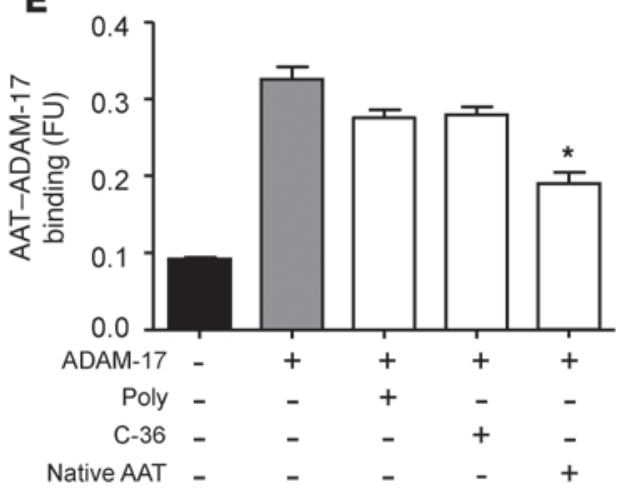

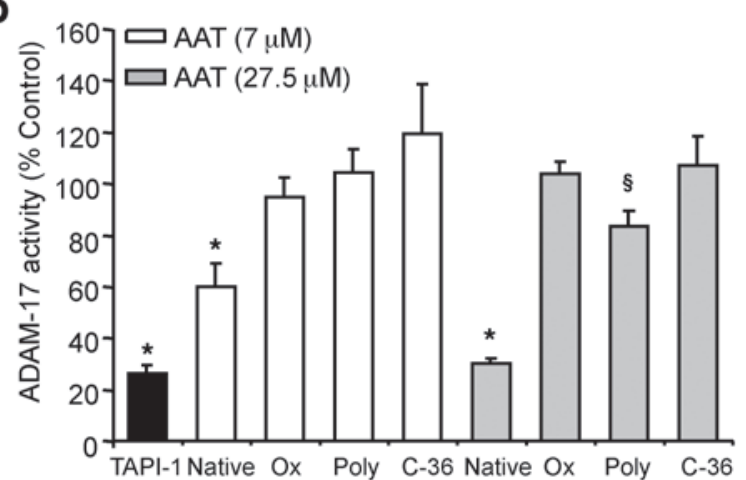

F

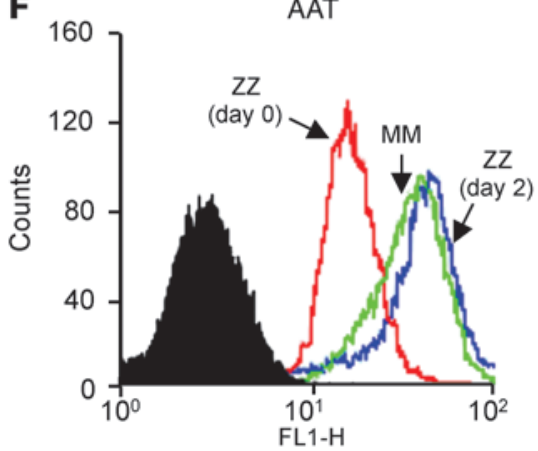

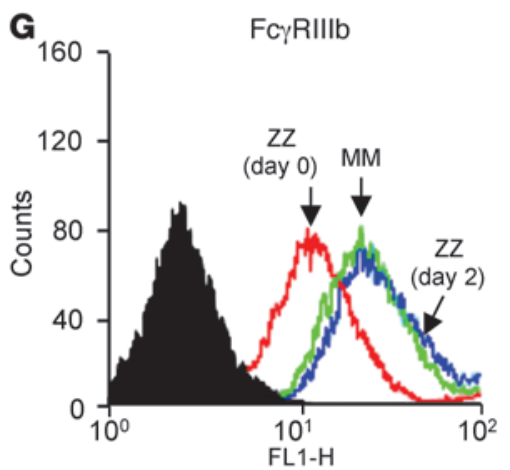

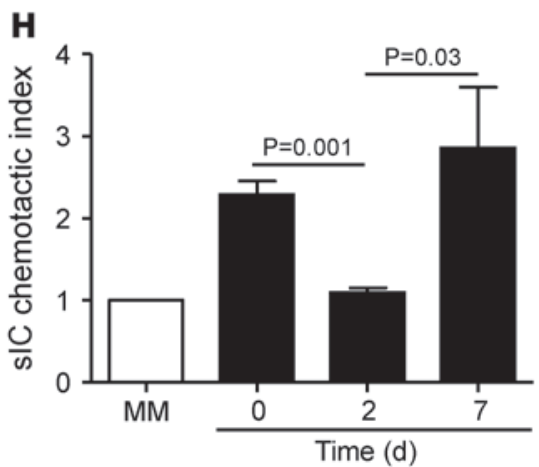

Figure 6

AAT prevents neutrophil chemotaxis in response to sIC through inhibition of ADAM-17 activity. (A) Western blots showing time course of sICinduced release of Fc $\gamma \mathrm{RIIIb}$ from MM neutrophils with or without TAPI-1 (10 mM). (B) Quantification of FcyRIIlb release from MM neutrophils treated with $\mathrm{sIC}(10 \% \mathrm{v} / \mathrm{v})$ with or without AAT $(27.5 \mathrm{mM})\left({ }^{\star} P<0.05\right)$. Inset: Western blot illustrating FcyRIIlb release at the $10-\mathrm{minute}$ time point. (C) Competitive inhibition of ADAM-17 by AAT. (D) The effect of oxidation (Ox), polymerization (Poly), or the cleaved AAT peptide (C-36 fragment) on TACE inhibition (percent inhibition of maximum activity) was compared with native AAT. * $P<0.05$, native AAT or TAPI- 1 versus maximal activity; $\$ P=0.008$, polymerized AAT versus native AAT $(27.5 \mathrm{mM})$. (E) Binding of ADAM-17 (250 ng) to immobilized AAT detected in the presence or absence of equimolar concentration of polymerized, C-36 fragment, or native AAT ( ${ }^{*} P=0.005$ ). Levels of membrane-bound AAT (F) and FcyRIIlb (G) on isolated resting control MM (green) and ZZ-AATD neutrophils before (red) and 2 days after augmentation therapy (blue). (H) The mean chemotactic index of ZZ-AATD neutrophils (black bars) toward sIC (10\% v/v) in serum (50\% v/v) was significantly reduced on day 2 when compared with day 0 and with day 7 after augmentation therapy. For comparative analysis, MM neutrophils treated with sIC (white bar) were set at a chemotactic index of 1 . Immunoblots in $\mathbf{A}$ and $\mathbf{B}$ are representative results from 1 of $\mathbf{3}$ separate experiments. B-E and $\mathbf{H}$ are the mean \pm SEM of triplicate experiments. $\mathbf{F}$ and $\mathbf{G}$ are representative results from 1 of 3 separate experiments.

of AAT by LC-MS/MS (Figure 5B). This finding was further supported by the presence of Fc $\gamma$ RIIII and AAT on Western blots of an immunoprecipitation for AAT (Figure 5C, top panel) and for FcyRIIIb, respectively (Figure 5C, lower panel). By expanding the gel filtration result illustrated in Figure 4E by Western blot analysis for
FcyRIIIb, we observed the coelution of AAT and FcyRIIIb in fraction 28 (Supplemental Figure 4A). Moreover, native gel electrophoresis and Western blot analysis of fraction 28 supported the possibility of an AAT-FcyRIIIb interaction, while excluding formation of AAT polymers or neutrophil elastase (NE) and PR3 as possible binding 
A

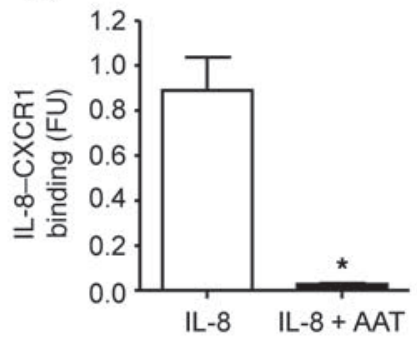

B

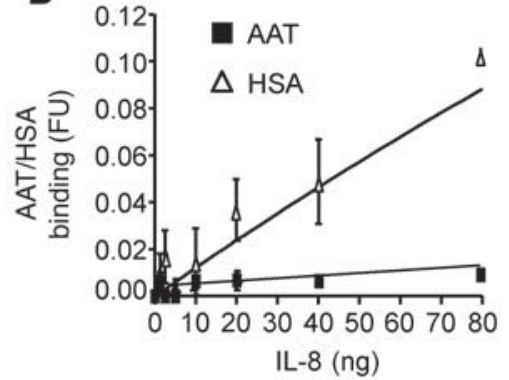

E

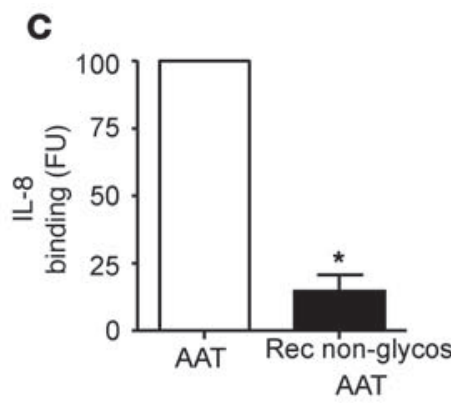

F

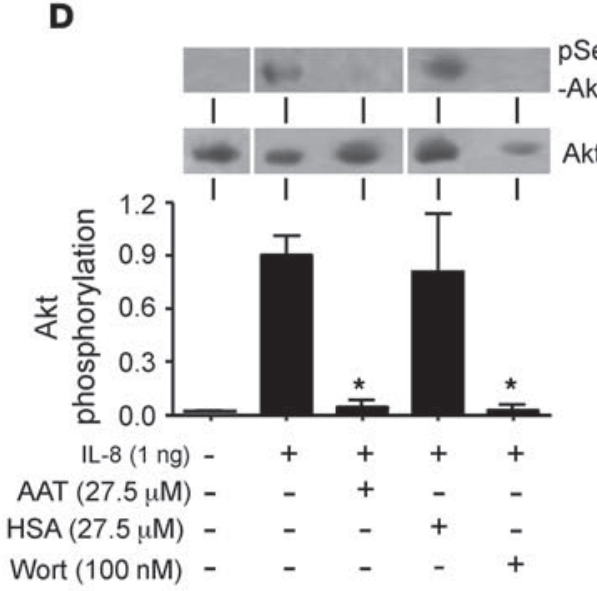

G

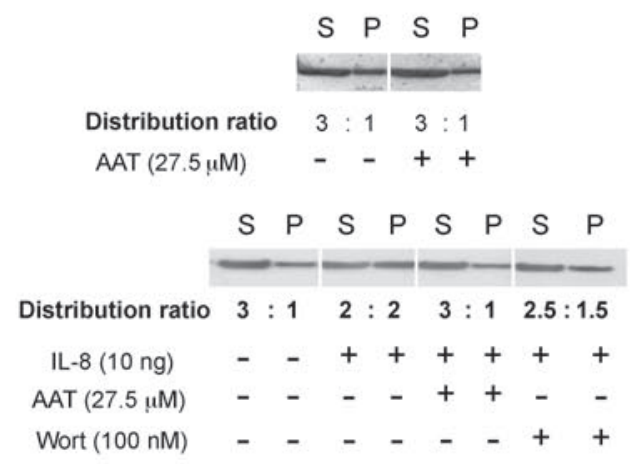

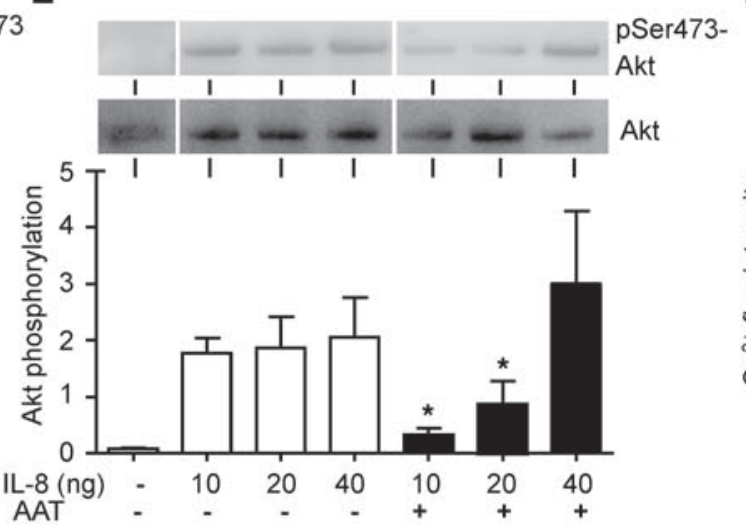

$(27.5 \mu \mathrm{M})$

H
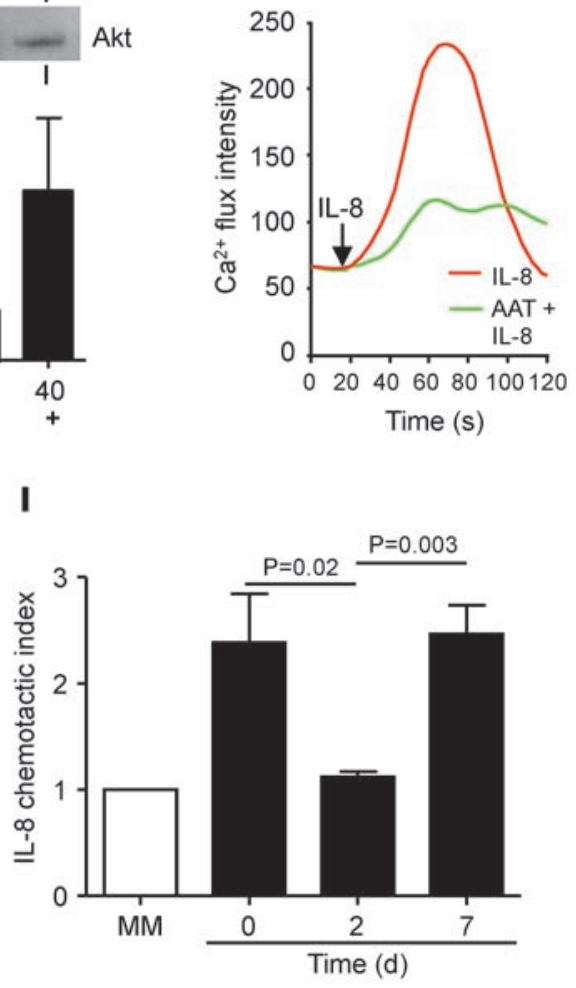

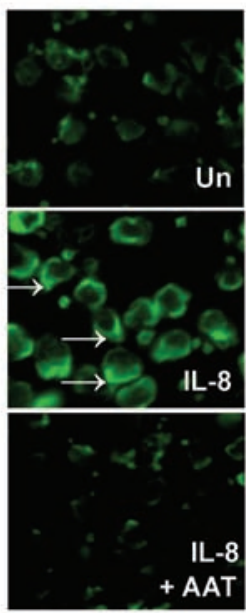

\section{Figure 7}

AAT binds IL-8 and modulates neutrophil chemotaxis by controlling CXCR1 binding. (A) Binding of IL-8 (10 ng) to immobilized CXCR1 was inhibited in the presence of AAT $(27.5 \mathrm{mM})\left({ }^{*} P=0.002\right)$. (B) Comparative binding of IL-8 to AAT and HSA. AAT (27.5 mM) bound approximately $20 \mathrm{ng} \mathrm{IL-8.} \mathrm{(C)} \mathrm{Comparative} \mathrm{binding} \mathrm{of} \mathrm{IL-8} \mathrm{to} \mathrm{serum} \mathrm{purified} \mathrm{AAT} \mathrm{and} \mathrm{recombinant} \mathrm{non-glycosylated} \mathrm{(Rec} \mathrm{non-glycos)} \mathrm{AAT} \mathrm{(}{ }^{\star} P=$ 0.001). (D) Expression levels of phospho-Akt Ser473 after IL-8 ( $1 \mathrm{ng} / 1 \times 10^{7}$ cells) treatment. Wortmannin (Wort, $\left.100 \mathrm{nM}\right)$ and AAT (27.5 mM), but not HSA, inhibited Akt activity efficiently ( ${ }^{*} P<0.05$ versus IL-8 control). (E) AAT (27.5 mM) significantly inhibited phosphorylation of Akt induced by $10 \mathrm{ng}$ and $20 \mathrm{ng} \mathrm{IL-}-8\left({ }^{*} P<0.05\right.$ versus IL-8 control). (F) Time course of changes in $\mathrm{Ca}^{2+}$ intensity in response to IL-8 (10 ng) with or without AAT $(27.5 \mathrm{mM})$. (G) AAT suppression of IL-8-induced actin cytoskeletal rearrangements. Immunoblot with anti-actin antibody for the distribution of G-actin (in the supernatant fraction [S]) and F-actin (in the pellet fraction [P]) in untreated or AAT-treated (27.5 mM) cells (top panel). Lower panel: IL-8-treated (10 ng) MM neutrophils with or without AAT or control Wort (100 nM). Distribution ratios are shown. (H) Confocal images of neutrophils (MM) undergoing chemotaxis in response to IL-8 (10 ng). F-actin at the leading edge of neutrophils (arrows) was not apparent in resting cells (Un) or cells treated with IL-8 plus AAT (27.5 mM) ( $\times 40$ magnification, $\times 10$ zoom). (I) IL-8-induced (10 ng) mean chemotactic index of ZZ-AATD neutrophils (black bars) on day 2 after therapy compared with day 0 and with day 7 after augmentation therapy. All experiments were performed in triplicate on 3 consecutive days, and each measurement is the mean \pm SEM. Images in $\mathbf{D}$ - $\mathbf{H}$ are representative results of 1 of 3 separate experiments. 


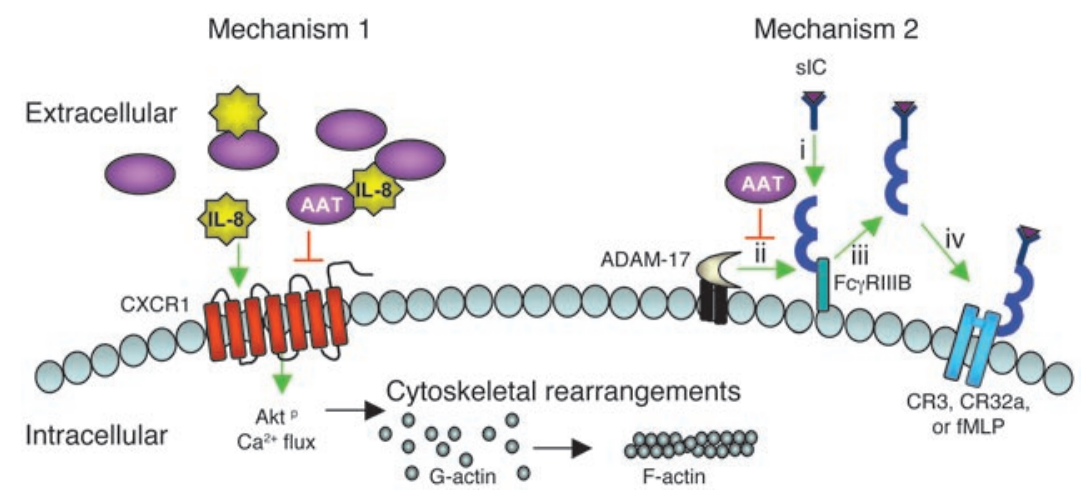

Figure 8

AAT regulates neutrophil chemotaxis through two different mechanisms. (A) In response to IL-8, cell activation is accompanied by Akt phosphorylation and $\mathrm{Ca}^{2+}$ flux, leading to F-actin formation and cytoskeletal rearrangements. In vivo, the resting circulating MM neutrophil is surrounded by a high concentration of AAT $(27.5 \mu \mathrm{M})$. AAT binds IL-8 and modulate CXCR1 engagement. (B) In response to SIC (i), ADAM-17 activity is increased (ii), causing shedding of the Fc $\gamma R$ Ill lb from the membrane (iii). Possible signaling mechanisms involve crosslinking with $\mathrm{CR} 3, \mathrm{CD} 32 \mathrm{a}$, or the fMLP receptor (iv) and migration of cells to the site of inflammation. AAT modulates chemotaxis by inhibiting ADAM-17 activ-

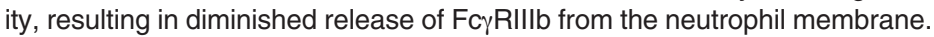

partners within this complex (Supplemental Figure 4B). The exposure of AAT-coated surfaces to Fc $\gamma$ RIIIb revealed that Fc $\gamma$ RIIIb bound to AAT in a concentration-dependent manner but not to a second non-GPI-linked IgG receptor, FcyRIIa (Figure 5D). In addition, an ELISA utilizing mouse capture antibody to Fc $\gamma$ RIIIb and goat detection antibody for AAT quantified significant levels of cell-free serum FcyRIIIb-AAT complex in serum of CF patients (Figure 5E). Reciprocal ELISA utilizing goat capture antibody to AAT and mouse detection antibody for Fc $\gamma$ RIIIb quantified considerably higher levels of AAT-Fc $\gamma$ RIIIb complex in CF serum, compared with $\mathrm{MM}$ and ZZ-AATD serum (Supplemental Figure 4C). Since AAT and FcyRIIIb coimmunoprecipitated, it also appeared logical that AAT and Fc $\gamma$ RIIIb would colocalize on the neutrophil membrane. Analysis by confocal microscopy indicated that, as expected, AAT (red) and Fc $\gamma$ RIIIb (green) stained the plasma membrane (ring-like staining at the edge of the cells) (Figure 5F), and superimposition of the two images clearly identified colocalization (yellow) of the two signals. We next tested the hypothesis that enzymatic cleavage of the GPI-anchored Fc $\gamma$ RIIIb with phosphatidylinositol-specific phospholipase C (PI-PLC) would also displace the associated AAT binding partner (Figure 5G). Western blot analysis of PI-PLC-treated $\left(1 \mathrm{U} / 1 \times 10^{6}\right.$ cells $)$ neutrophil membranes resulted in release of AAT and Fc $\gamma$ RIIIb, but not p22 phox , a control non-GPI membrane component. Further treatment of membranes with $\mathrm{NaCl}(350 \mathrm{mM})$ caused release of AAT but not Fc $\gamma$ RIIIb (Figure 5G). In addition, in comparison to MM donors, neutrophils of ZZ-AATD patients showed a significant decrease in the level of $\mathrm{Fc} \gamma \mathrm{RIIIb}$ protein (Figure 5H and Supplemental Figure 4D). The observation that levels of Fc $\gamma$ RIIIb were significantly elevated in serum of ZZ-AATD patients compared with normal MM controls $(P=0.01)$ (Figure 5I) contrasts results illustrating similar levels of Fc $\gamma$ RIIIb-AAT complex (Figure 5E), possibly indicating that a proportion of Fcy RIIIb in ZZ-AATD serum is AAT unbound. Collectively, these experiments further suggest Fc $\gamma$ RIIIb as a binding partner that is necessary for AAT membrane presentation and suggest that AAT may functionally impact on maintaining Fc $\gamma$ RIIIb membrane expression.
AAT regulates release of $F \mathrm{C}$ RIIIb by inhibiting metalloprotease ADAM-17 activity. Evidence exists that neutrophil chemotaxis requires activity of surface sheddases, including ADAM-17, which has been implicated in the shedding of Fc $\gamma$ RIIIb (19), a prerequisite for neutrophil chemotaxis (20-23). This was confirmed when cells were exposed to sIC $(10 \% \mathrm{v} / \mathrm{v})$ and the extracellular supernatants analyzed by Western blot for the presence of released FcyRIIIb (Figure 6A). Release of FcyRIIIb was observed at 5 and 10 minutes after exposure, an effect greatly reduced by the specific ADAM-17 inhibitor TAPI-1 $(10 \mu \mathrm{M})(24)$. To investigate the possibility that AAT regulated sIC-induced chemotaxis by modulating shedding of Fcy RIIIb, we exposed cells to sIC $(10 \% \mathrm{v} / \mathrm{v})$ in the presence or absence of AAT and monitored the kinetics of Fc $\gamma$ RIIIb shedding by immunoblotting. As illustrated in Figure 6B, AAT inhibited the release of Fcy RIIIb elicited by sIC at 5 and 10 minutes by $58 \% \pm 1.2 \%$ and $69 \% \pm 5.9 \%$, respectively $(P<0.05)$. The ability of AAT to directly inhibit ADAM-17 activity was analyzed fluorometrically, and the results indicated that AAT inhibited ADAM-17 enzymatic activity with a $K_{i}$ value of $5.7 \mu \mathrm{M}$ (Figure 6C). In addition, an equimolar concentration of AAT competitively inhibited ADAM-17, with an association rate constant of $2.23 \times 10^{4} \pm 0.37 \times 10^{4} \mathrm{M}^{-1} \mathrm{~s}^{-1}$, although this may underestimate the physiological inhibitory capacity, as AAT is one of the most abundant proteins in the circulation. As polymerization and oxidation have previously been shown to alter enzymatic activity of AAT against NE, we tested whether an intact reactive center loop was also essential for inhibiting ADAM-17 activity. As illustrated in Figure 6D, a loss of anti-ADAM-17 activity was observed following oxidation of AAT with N-chlorosuccinimide, heat-induced polymerization, or by the AAT cleavage product C-36. Additionally, results revealed a significant $68 \%$ reduction in ADAM-17 activity in the presence of $27.5 \mu \mathrm{M}$ AAT $(P=0.001)$, a value comparable to inhibition of ADAM-17 activity by TAPI-1 (10 $\mu \mathrm{M})$ (Figure 6D). Moreover, the exposure of AAT-coated surfaces to ADAM-17 $(250 \mathrm{ng})$ together with native AAT $(250 \mathrm{ng})$ reduced the level of detectable bound ADAM-17 by approximately $36 \%(P=0.005)$, a competitive effect not observed with either polymerized AAT or the C-36 cleaved fragment of AAT (Figure 6E). From these experiments, we conclude that neither polymers nor the C-terminal fragment of AAT can inhibit binding of native AAT to ADAM-17.

We next explored the effect of intravenous augmentation therapy on FcyRIIIb expression in vivo. Two days after treatment, ZZ-AATD $(n=4)$ patients possessed serum AAT concentrations slightly elevated above MM control serum levels $(30.51 \pm 1.9 \mu \mathrm{M}$ and $24.8 \pm 0.68 \mu \mathrm{M}$ AAT, respectively) (Supplemental Figure 5) but also significantly greater than on day 0 (pretreatment) $(6.3 \mu \mathrm{M}$ AAT, $P<0.0001)$ and 7 days after treatment $(13.72 \mu \mathrm{M}$ AAT, $P<0.0001)$. Results revealed that infused AAT bound to circulating neutrophils (Figure 6F), as a significant increase in the level of membrane-bound AAT was detected on day 2 after therapy (mean fluorescence, 43) compared with day 0 (mean fluorescence, 17.23; $P<0.001)$. In addition, downregulation of Fc $\gamma$ RIIIb was observed on $\mathrm{ZZ}$ compared with MM control cells before therapy (Fc $\gamma \mathrm{RIIIb}$ mean fluorescence: ZZ-AATD day 0, 16.94; control MM, 29.35; $P<0.001$ ) (Figure 6G). However, on day 2 after treatment, an increase in the 
level of FcyRIIIb-expressing ZZ neutrophils was observed, comparable to that in $\mathrm{MM}$ controls and significantly greater than on day 0 (Fc $\gamma$ RIIIb mean fluorescence: ZZ-AATD day 2, 30.41; $P<0.001$ ). A chemotaxis assay toward $\operatorname{sIC}(10 \% \mathrm{v} / \mathrm{v})$ in the presence of respective $\mathrm{ZZ}$ and $\mathrm{MM}$ sera revealed that $\mathrm{ZZ}$ neutrophils on day 2 after augmentation therapy had a chemotactic index similar to that of the MM neutrophils and which was significantly reduced compared with day 0 and with day 7 after treatment $(P=0.001$ and $P=0.03$, respectively) (Figure $6 \mathrm{H}$ ).

Collectively, these experiments provide evidence for the mechanism by which native AAT modulates neutrophil chemotaxis in response to sIC and illustrate the ability of AAT to bind the circulating neutrophil in vivo and prevent release of $\mathrm{Fc} \gamma \mathrm{RIIIb}$ from the neutrophil membrane, via inhibitory activity against ADAM-17.

$A A T$ regulates $I L-8$-induced chemotaxis by modulating interaction with CXCR1. To understand the possible mechanism by which AAT inhibits IL-8-induced chemotaxis, we first explored the ability of AAT to modulate ligand binding to CXCR1. The exposure of CXCR1-coated surfaces to IL- 8 in the presence or absence of AAT $(27.5 \mu \mathrm{M})$ revealed that AAT blocked the ability of IL-8 (10 ng) to engage with CXCR1 (Figure 7A). This result implied direct binding of AAT to IL-8, and as IL-8 interacts with glycosaminoglycans with high affinity (24-26), we hypothesized that binding of IL-8 to glycosylated AAT may modulate IL-8-induced chemotaxis. To challenge this hypothesis, we exposed surfaces coated with AAT at a concentration of $27.5 \mu \mathrm{M}$ to increasing concentrations of IL-8, and the plateau level of maximum binding observed was approximately $20 \mathrm{ng}$ IL-8/ $\mathrm{cm}^{2}$ (Figure 7B). In contrast, binding of IL-8 to HSA (control protein) remained linear. The importance of glycosylated moieties of AAT for successful IL-8 binding was confirmed, as nonglycosylated recombinant AAT produced in E. coli failed to bind IL-8 (Figure 7C). The impact of IL-8 binding to AAT or HSA on its ability to stimulate Akt Ser473 phosphorylation, a key step in IL-8mediated neutrophil chemotaxis (27), was explored. Figure 7D shows that IL-8 (1 ng) stimulated adequate Akt phosphorylation after just 10 minutes and that this effect was unaffected by prebinding of IL-8 to HSA $(27.5 \mu \mathrm{M})$. In contrast, pre-binding of IL-8 to AAT $(27.5 \mu \mathrm{M})$ inhibited IL-8-mediated Akt Ser473 phosphorylation to the level observed after the inclusion of the phosphatidylinositol 3-kinase inhibitor wortmannin. Additionally, binding of IL-8 to AAT $(27.5 \mu \mathrm{M})$ significantly reduced IL-8 neutrophil Akt phosphorylation in response to both 10 and 20 ng IL- 8 by approximately $81 \%$ and $62 \%$, respectively $(P<0.05)$ (Figure $7 \mathrm{E}$ ). Conversely, however, AAT had no effect on Akt Ser473 phosphorylation stimulated by $40 \mathrm{ng}$ IL-8, illustrating that the described inhibitory effect can be overcome. In addition, an increase in cytoplasmic $\mathrm{Ca}^{2+}$ (calcium flux) is central to the transduction of neutrophil response to IL-8 (28), and changes in average Fluo-4 NW emission in IL-8-stimulated (10 ng) cells was measured over the course of 2 minutes (Figure 7F). IL-8 caused a robust increase in intracellular calcium that reached a peak after 50 seconds, and in comparison the level of intracellular calcium release in the presence of AAT was greatly diminished.

Remodeling of the actin cytoskeleton is a prerequisite for the chemotactic process, and to analyze the effect of AAT on the redistribution of F- versus G-actin after IL-8 exposure, we employed a biochemical assay to analyze in situ F-actin levels. While AAT $(27.5 \mu \mathrm{M})$ on its own had no effect, IL-8 (10 ng) induced a substantial change in the ratio of G-actin (supernatant fraction) versus F-actin (pellet fraction) (Figure $7 \mathrm{G})$. The presence of AAT or wortmannin $(100 \mathrm{nM})$ as a control suppressed IL-8-induced F-actin formation. Since coronin is an F-actin-interacting protein solubilized upon neutrophil stimulation (29), we analyzed whether AAT could impact on the solubilization of coronin-1 in response to IL-8. As illustrated in Supplemental Figure 6, AAT $(27.5 \mu \mathrm{M})$ significantly reduced the level of soluble coronin- 1 by $40 \%(P=0.01)$. In addition, polarization of $\mathrm{F}$-actin to the leading edge during neutrophil chemotaxis was greatly diminished in the presence of a physiological concentration of AAT (Figure $7 \mathrm{H}$ ). Confocal microscopy images illustrated that resting neutrophils had punctuate F-actin staining intensity similar to that of cells treated with IL-8 in the presence of AAT, indicative of sites of contact between cell and substratum (30), rather than polarization. Results also revealed that in response to IL-8 $(10 \mathrm{ng})$, in the presence of respective $\mathrm{ZZ}$ and $\mathrm{MM}$ sera, $\mathrm{ZZ}$ neutrophils on day 2 after augmentation therapy showed a chemotactic index that was similar to the MM controls and was also significantly reduced compared with $\mathrm{ZZ}$ neutrophils on day 0 and on day 7 after treatment $(P=0.02$ and $P=0.003$, respectively) (Figure $7 \mathrm{I})$. Taken together, these data suggest that glycosylated AAT-IL-8 complex formation determines CXCR1 engagement, and in this process AAT functions as a negative regulator of cell chemotaxis.

\section{Discussion}

In patients with AATD, the development of emphysema is believed to be caused by the unchecked action of proteases on lung tissue. However, this long-standing dogma on the sole function of AAT as an anti-serine protease has been questioned in the last several years, with a number of antiinflammatory roles being described for AAT $(1-3,5)$. Studies have shown that native AAT may modulate immune cell function of neutrophils $(4,6,31)$, monocytes $(1,3,32)$, and T cells (33), and the results of this study are analogous to data demonstrating the inhibitory effect of AAT on AMLP-induced neutrophil migration in vitro (4). Moreover, this study elucidates what we believe to be a novel role for AAT and has uncovered the ability of AAT to inhibit chemotactic response of both CXCR1 and Fcy RIIIb receptor signaling by divergent mechanisms. The first involves AAT-IL-8 complex formation consequently inhibiting IL-8-CXCR1 interaction, and the second concerns the ability of AAT to control sIC-induced neutrophil chemotaxis by modulating ADAM-17 activity, thus impeding Fc $\gamma$ RIIIb release from the cell membrane (Figure 8).

AAT has been shown to reduce neutrophil infiltration into kidneys during ischemia/reperfusion (34), and this essential inhibitory effect of AAT on circulating neutrophils prompted us to investigate the chemotactic response of AATD neutrophils donated by clinically stable ZZ-AATD patients compared with normal MM control cells. The findings of enhanced IL-8-induced chemotaxis are in keeping with a pivotal role for AAT in modulation of cell activity. In support of this theory, increasing concentrations of AAT exhibited significant inhibition of neutrophil migration toward IL-8. The observed reduction in chemotaxis by AAT was, however, alleviated by increasing the concentration of chemoattractant, suggesting that this inhibitory effect may be overcome in the presence of sufficient chemokine. In agreement with the results of others (35), we found that AMLP alone only poorly activated the NADPH oxidase of isolated MM neutrophils, and pronounced oxidase activity was only noted after TNF- $\alpha$ priming (Supplemental Figure 7), thus confirming the isolation of unprimed cells within this study. Isolation procedures used to obtain purified neutrophils and priming agents such as GM-CSF and TNF- $\alpha$ can enhance neutrophil activity, leading to an increased respiratory burst and 
elevated levels of superoxide production (36). This may explain the variance between our findings and a previous study that reported comparable activity between control and ZZ-AATD neutrophils (37), a disparity possibly arising due to the use of an alternate cell purification protocol and the successful isolation of nonprimed cells within our study.

Our results suggest a sensing mechanism in cells that has not to our knowledge been previously described, and experiments demonstrate that neutrophils can migrate down a functional gradient of AAT in response to an increasing gradient of IL-8. The interaction of inflammatory molecules with glycosaminoglycans has been hypothesized to provide a mechanism for establishing chemokine gradients in order to provide directional signals for migrating cells (38). Most chemokines, including IL-8, interact with glycosaminoglycans via charge complementation (26), as they are basic proteins, while glycosaminoglycans are acidic polymers. Moreover, it has previously been shown that IL- 8 binds heparan sulfate and that this interaction facilitates binding of the cytokine to its specific receptor, thus prolonging IL-8 activity (39). CXCR1 is specific for IL-8 (40, 41), and within this study we have found that IL-8 interacts with glycosylated AAT, but rather than facilitating IL-8 activity, physiological concentrations of AAT inhibit CXCR1 engagement of up to $20 \mathrm{ng}$ of IL-8, thereby preventing downstream signaling events including Akt phosphorylation, calcium flux, and chemoattractant-induced cytoskeletal rearrangements. This antiinflammatory effect is not exclusive to AAT, as it has also been reported that the plasma glycoprotease inhibitor $\alpha-2$ macroglobulin creates a complex with IL-8, resulting in reduced neutrophil infiltration into the lungs compared with IL-8 controls (42). AAT and $\alpha-2$ macroglobulin are acute-phase reactants, and as both proteins show a rise in mean value after infection, it is tempting to speculate that the increased levels of both serum proteins function to dampen down the inflammatory response after infection by binding and inactivating IL-8 activity. With regard to AATD, this AAT gradient is grossly disrupted, impacting on both interstitium and lung concentrations of AAT and the potential for neutrophil-mediated interstitial emphysema in AATD (43). In addition, the inability of E. coli-derived nonglycosylated AAT to bind and modulate the activity of IL-8 is of clinical importance. Indeed, while aerosolized nonglycosylated AAT may boost the natural antiprotease within the AATD lung (44), the results of the present study suggest added beneficial therapeutic effects of infused glycosylated AAT. The major outcome of augmentation therapy is a rise in blood AAT to levels usually referred to as being at the "protective" threshold. Studies have demonstrated that infusions of AAT are safe and can reverse the biochemical abnormalities in serum and lung fluid (12). In addition, there have been some recent studies on the clinical efficacy of AAT augmentation therapy beyond these biochemical considerations (45-48), although the way in which AAT confers these clinical benefits is not fully known. The present study illustrates that AAT augmentation therapy impacts on the circulating neutrophil and demonstrates that infused AAT fulfills an antiinflammatory role in vivo by modulating neutrophil chemotaxis.

This investigation elucidates a hitherto undescribed localization of neutrophil-associated AAT. AAT has previously been localized within primary granules containing neutrophil elastase and proteinase 3 (PR3) $(15,49)$; however, there remained a paradox as to why an enzyme and cognate inhibitor would simultaneously compartmentalize, potentially impeding protease-dependent antimicrobial activity. Our study reports the finding that both neutrophil-derived and serum-absorbed AAT bind the circulating neutrophil and that approximately $80 \%$ of cellular AAT is localized to the plasma membrane within lipid rafts and to a lesser extent within secretory vesicles. Further experiments employing confocal fluorescence microscopy and flow cytometry confirmed that AAT in resting MM neutrophils is bound to the outer membrane of the cell. Slight heterogeneity in molecular mass of membrane-associated isoforms of AAT was revealed by $2 \mathrm{D}$ electrophoresis, possibly relating to the described variable composition of sialic acids on various glycosylation sites (50). In addition, low circulating serum levels of AAT correlated with a concomitant reduction in the AAT membrane protein composition of ZZ-AATD neutrophils.

Rather than secretion of AAT from internal stores following full cell activation with combined cytochalasin B and fMLP stimuli (49), flow-cytometric analysis clearly showed that the inflammatory mediators IL- 8 and TNF- $\alpha$, in a concentration-dependent manner, induced the release of membrane-associated AAT by neutrophils. Gel filtration chromatography and immunoprecipitation analysis revealed that AAT was released from the cell membrane in a protein complex with its membrane-binding partner Fc $\gamma$ RIIIb. In addition, released AAT was capable of forming irreversible complexes with purified NE. This last result is important, as it specifically shows that degranulation of primary granules did not occur during IL-8 treatment and also that AAT did not interact with the neutrophil membrane via NE, PR3, or cathepsin G, which have previously been proposed to bind hydrophobic or low-affinity proteoglycan moieties of neutrophil membranes (51). Fc RIIIb (40-60 kDa) is expressed by neutrophils and basophils (52) and is unique in that it is the only $\mathrm{Fc}_{\mathrm{c}}$ receptor linked to the plasma membrane by a GPI anchor. In line with our results for AAT, Fc $\gamma$ RIIIb has also been found associated with membrane lipid rafts (53), and in our study confocal laser microscopy showed membrane colocalization of AAT and FCyRIIIb in intact cells. Of note, a substantial amount of AAT was removed from the MM neutrophil membrane following treatment with either PI-PLC or $\mathrm{NaCl}$, indicating that AAT interacts electrostatically with this GPI-linked low-affinity IgG receptor. Of relevance, within this study we found that low membrane-associated AAT correlated with a significant reduction in the FcyRIIIb membrane protein composition of ZZ-AATD neutrophils, most likely due to ADAM-17 activity. This latter result may explain the observed reduced ZZ-AATD cell chemotaxis in response to sIC when assays were performed in PBS, as the importance of normal FcyRIIIb expression for sIC-mediated neutrophil recruitment has been previously shown (20). In vivo, however, signaling and chemotaxis through Fc $\gamma$ RIIIb has been shown to occur by shedding of this mobile receptor and co-capping via lectin-saccharide binding or cross-linking of FcyRIIIb with CR3, CD32a (54), or the fMLP receptor (21). For this reason, reduced chemotactic capacity of ZZ-AATD neutrophils suspended in PBS in response to sIC in vitro does not reflect in vivo conditions. To more closely imitate in vivo conditions, we evaluated the chemotactic index of MM and ZZ-AATD neutrophils toward sIC in the presence of respective $\mathrm{MM}$ and $\mathrm{ZZ}$ sera. The mean chemotactic index value of ZZ-AATD neutrophils was found to be significantly higher than that of MM control cells. When AATD serum with sIC was employed, soluble FcyRIIIb re-bound the ZZ-AATD neutrophil membrane (Supplemental Figure 8), initiating a signaling cascade leading to increased chemotaxis. sIC does not bind AAT and AAT does not inhibit binding of sIC to the cell surface (our unpublished observations), suggesting that AAT inhibition of ADAM-17 enzymatic activity is central to its inhibitory effect on neutrophil chemotaxis to sIC. 
Shedding of FcyRIIIb from the neutrophil membrane (55) is involved in immune complex-stimulated neutrophil recruitment in vivo (20). Both metalloproteases and serine proteases have been implicated in the cleavage of Fc $\gamma$ RIIIb (56), but the most likely candidates are members of the ADAM family of metalloproteases (57). Evidence exists that neutrophil chemotaxis requires surface sheddase activity, and ADAM-17 has been implicated in the shedding of FcyRIIIb (58). Our results indicate that the anti-chemotaxis effects of AAT in response to sIC may be mediated by inhibition of ADAM-17, resulting in decreased shedding of Fcy RIIIb. In support of this theory, neutrophils isolated from ZZ-AATD individuals before augmentation therapy possessed low levels of membrane-associated Fc $\gamma$ RIIIb, and results after augmentation therapy showed that newly produced Fc $\gamma$ RIIIb-expressing cells contained an optimal concentration of bound AAT. Inhibition of ADAM-17 activity by serine-protease inhibitors (tosyl-L-lysine chloromethyl ketone) has previously been recognized (59) and further confirmed by this study. Native AAT, but not oxidized or polymerized AAT, inhibited ADAM-17 activity, indicating that an intact serpin-reactive center loop was required for the AAT-ADAM-17 inhibition. In addition, neither polymerized AAT nor the C-36 cleaved fragment of AAT could inhibit the AAT-ADAM-17 binding event. Such broad-spectrum activity of AAT is supported by its ability to abrogate cysteine-aspartic acid protease activity (5). In addition, AAT illustrates acute antiinflammatory effects similar to that of the metalloprotease inhibitor RS113456 (60). In support of our results, AAT has been shown to reduce neutrophil infiltration into lung tissue after intratracheal silica administration and after cigarette smoke-induced emphysema (61). Furthermore, the ability of AAT to inhibit ADAM-17 activity has been postulated in studies investigating shedding of TNF- $\alpha$ from islet cells (62).

In summary, our study has found that AAT modulates the chemotactic response of CXCR1 signaling by binding IL-8 and inhibiting receptor engagement. Additionally, AAT modulates neutrophil chemotaxis in response to sIC by inhibiting ADAM-17 activity, thereby decreasing release of Fc $\gamma$ RIIIb from the neutrophil membrane. After augmentation therapy in ZZ-AATD individuals, increased serum levels of AAT function to bind IL-8- and Fc $\gamma$ RIIIbexpressing neutrophils, thereby inhibiting ADAM-17, and in turn normalizing excessive AATD neutrophil chemotactic responses. Consequently, this study delineates a key antiinflammatory role for AAT in neutrophil chemotaxis and supports the possibility of additional benefits of AAT augmentation therapy in AATD.

\section{Methods}

Chemicals and reagents. All chemicals and reagents were of the highest purity and endotoxin free and were purchased from Sigma-Aldrich unless otherwise indicated.

Patient groups. Control volunteers $(n=6$, mean age $32.14 \pm 1.86)$ showed no evidence of any disease and had no respiratory symptoms; none were on medication, and all had MM phenotype, with serum AAT concentrations within the normal range $(25-50 \mu \mathrm{M})$.

Asymptomatic ZZ-AATD individuals, not receiving augmentation therapy, were recruited from the Irish Alpha One Antitrypsin Deficiency Registry $(n=6$, mean age $39.6 \pm 7.07)$. Patients were clinically stable, with no evidence of exacerbations in the previous 6 months. Forced expiratory volume in 1 second (FEV1) was $97.6 \% \pm 14.08 \%$ predicted.

ZZ-AATD patients $(n=4$, mean age $56.5 \pm 2.65$, FEV1 $52.25 \% \pm 8.27 \%$ predicted) on augmentation therapy were receiving plasma-purified AAT from CSL Behring (Zemaira), given intravenously at a dosage of $60 \mathrm{mg} / \mathrm{kg}$ body weight weekly. In the 4 weeks prior to obtaining blood samples, all patients were exacerbation free. One patient with ZZ-AATD who had undergone an uncomplicated liver transplantation 30 months prior to sampling was recruited (age 46.6 years, FEV1 56\% predicted).

Serum samples were collected from CF patients $(n=4)$ who presented for treatment of acute exacerbation of the disease. Full informed patient consent was obtained for all procedures, and ethical approval for the use of blood samples was obtained from the Beaumont Hospital Ethics Review Board.

Preparation of human neutrophils and functional assays. Neutrophils were isolated as previously described (63) and resuspended in PBS or respective serum $(50 \% \mathrm{v} / \mathrm{v})\left(2.5 \times 10^{5} \mathrm{cells} / 200 \mu \mathrm{l}\right)$. Chemotaxis assays were performed by measuring the percentage of neutrophils migrating toward optimal concentrations of IL-8 (1-40 ng) (R\&D Systems) or sICs (10\% v/v) (64) in the presence or absence of AAT (0.2-27.5 $\mu \mathrm{M}$; Athens Research \& Technology), TAPI-1 $(10 \mu \mathrm{M})$, or HAS $(27.5 \mu \mathrm{M})$ by employing a multiwell chemotaxis chamber (Neuro Probe Inc.), and data were presented as chemotactic index as previously described (65). For comparative analysis, the PBS control or MM neutrophils treated with IL-8 were set at a chemotactic index of 1, as indicated.

Checkerboard analysis was performed to differentiate chemotactic from chemokinesis activity as previously described (66). NADPH oxidase activity as measured by superoxide $\left(\mathrm{O}_{2}^{-}\right)$production was quantified by $\mathrm{O}_{2}{ }^{-}$dismutase-inhibitable reduction of cytochrome $c$ at $550 \mathrm{~nm}$ (63). Intracellular calcium levels were quantified using the Fluo-4 NW calcium kit (Invitrogen) according to the manufacturer's instructions.

$1 D$ and $2 D$ gel electrophoresis and Western blot analyses. Samples were subjected to 1D SDS-PAGE under denaturing conditions and to native gel electrophoresis in a NativePAGE Novex Bis-Tris gel system (Invitrogen) following the manufacturer's instructions. 2D isoelectric focusing (IEF) was performed with $100 \mu \mathrm{g}$ of protein loaded onto 7-cm IPG strips (GE Biosciences) using the IPGphor focusing system (GE Biosciences), and for the second dimension samples were electrophoresed on 10\% SDS-PAGE gels.

After electrophoresis, gels were stained with Coomassie blue R250 for visualization of proteins, or alternatively proteins were transferred onto $0.2-\mu \mathrm{m}$ nitrocellulose or PVDF membrane by Western blotting. Blots were incubated with $1.0 \mu \mathrm{g} / \mathrm{ml}$ polyclonal rabbit or goat anti-AAT specific antibody (Abcam) or $0.2 \mu \mathrm{g} / \mathrm{ml}$ polyclonal rabbit anti-myeloperoxidase (anti-MPO) antibody (Abcam), polyclonal rabbit anti-p22 $2^{\text {phox }}$, polyclonal rabbit anti-flotillin, or polyclonal goat or monoclonal anti-Fc $\gamma$ RIIIb specific antibody (R\&D Systems). Additional primary antibodies included $1.0 \mu \mathrm{g} / \mathrm{ml}$ monoclonal antiactin antibody (Millipore), polyclonal rabbit anti-PR3, anti-HSA, anti-HLA class I, and anti-coronin-1 (Santa Cruz Biotechnology Inc.). Determination of Akt phosphorylation by Western blot analysis was as previously described (67). The secondary antibodies were HRP-linked anti-rabbit, -goat, or -mouse IgG (Cell Signaling Technology). Immunoreactive protein bands were visualized by employing SuperSignal West Pico Chemiluminescent Substrate (Pierce) after exposure to Kodak X-Omat LS Film. Controls for Western blotting included recombinant human (Rh) FcyRIIIb (R\&D Systems) or serum purified AAT. A Sebia isoelectrofocusing kit was employed for AAT phenotyping with the HYDRASYS system as previously described (16).

Culturing and subcellular fractionation of neutrophils. Isolated MM or ZZ neutrophils were lysed and fractionated (63) and neutrophil secretory vesicles and membranes further purified as previously described (68). HSA and HLA class I, respectively, were employed as markers of secretory vesicles and plasma membranes, as previously described (69). Membrane lipid raft fractions were isolated (70) in the presence and absence of $10 \mathrm{mM} \mathrm{M \beta CD}$. Quantification of F- and G-actin was carried out as previously described (71).

To investigate whether neutrophils synthesized AAT to substitute for membrane-released AAT, neutrophils $\left(2 \times 10^{7} / \mathrm{ml}\right)$ were cultured in RPMI supplemented with penicillin $(100 \mathrm{U} / \mathrm{ml})$ and streptomycin $(100 \mu \mathrm{g} / \mathrm{ml})$ and treated with IL-8 (10 ng, 10 minutes, $37^{\circ} \mathrm{C}$ with $\left.5 \% \mathrm{CO}_{2}\right)$. An aliquot 
$(300 \mu \mathrm{l})$ was removed, and the cells were pelleted by centrifugation $(500 \mathrm{~g}$, 5 minutes at $4^{\circ} \mathrm{C}$ ). The supernatant was collected and the cell pellet processed for isolation of membranes. The remaining cells were incubated for a further 4 and 16 hours $\left(37^{\circ} \mathrm{C}\right.$ with $\left.5 \% \mathrm{CO}_{2}\right)$ in fresh medium with supernatants and cell membranes collected at each time point (69). Western blot analysis was carried out to quantify membrane and released levels of AAT.

Confocal immunofluorescence. Isolated cells were fixed with $4 \%(\mathrm{w} / \mathrm{v})$ paraformaldehyde, and after blocking, cells were incubated with $1 \mu \mathrm{g} / \mathrm{ml}$ FITC-labeled goat anti-AAT (Abcam) and mounted employing Vectashield mounting medium with DAPI for nuclear staining (Vectashield Lab). For colocalization of AAT with Fc $\gamma \mathrm{RIIIb}, 1 \mu \mathrm{g} / \mathrm{ml}$ rabbit polyclonal anti-AAT was employed, followed by rhodamine-labeled goat secondary antibody (Abcam) and $1 \mu \mathrm{g} / \mathrm{ml}$ of a mouse anti-Fc $\gamma$ RIIIb, followed by a FITClabeled bovine secondary antibody (Santa Cruz Biotechnology Inc.). All immunofluorescence slides were viewed and images acquired using a Zeiss LSM710 confocal immunofluorescence microscope. The controls for this experiment included cells alone, nonspecific isotype control IgG, a control stain to prove cells were non-permeabilized (mouse anti-actin; Santa Cruz Biotechnology Inc.), and cells exposed only to secondary antibody.

In additional experiments, chemotactic neutrophils were produced as previously described (30). In brief, cells were resuspended in PBS on Polysine microscope slides (AGB Scientific Ltd.), after which they were incubated at $25^{\circ} \mathrm{C}$ for 5 minutes and then at $37^{\circ} \mathrm{C}$ for 5 minutes. Cells were incubated in the presence or absence of IL-8 $(10 \mathrm{ng})$ with or without AAT $(27.5 \mu \mathrm{M})$ for 10 minutes at $37^{\circ} \mathrm{C}$. Cells were then fixed with $4 \%(\mathrm{w} / \mathrm{v})$ paraformaldehyde in PBS for 10 minutes, permeabilized with $0.2 \%(\mathrm{v} / \mathrm{v})$ Triton X-100 in PBS for 10 minutes, and blocked for 1 hour with 3\% (w/v) BSA in PBS. The formation of F-actin at the leading edge of chemotactic cells was visualized with FITC-labeled phalloidin ( $50 \mu \mathrm{g} / \mathrm{ml}$ in PBS). Cells were stained for 45 minutes and then washed in PBS to remove unbound label.

Flow cytometry. Relevant cells remained untreated or treated with sIC $(10 \% \mathrm{v} / \mathrm{v})$ in the presence or absence of respective serum $(50 \% \mathrm{v} / \mathrm{v})$, TNF- $\alpha$, or IL-8 $\left(10 \mathrm{ng} / 2 \times 10^{7}\right.$ cells $)$ for 10 minutes at $37^{\circ} \mathrm{C}$. Neutrophils were fixed ( $4 \% \mathrm{w} / \mathrm{v}$ paraformaldehyde) and blocked ( $2 \% \mathrm{w} / \mathrm{v}$ BSA) for 1 hour and incubated with FITC-labeled goat polyclonal anti-AAT ( $1 \mu \mathrm{g} / 10^{6}$ cells $)$ (Abcam) or PE-conjugated mouse anti-L-selectin or mouse anti-FcyRIIIb, followed by a FITC-labeled bovine secondary antibody. Control samples were exposed to relevant nonspecific isotype control IgG or secondary labeled antibody alone and fluorescence determined by flow cytometry. A total of 10,000 events were collected. The data were analyzed using BD CellQuest Pro software.

Analysis of AAT release from the neutrophil membrane. Isolated neutrophils were treated with TNF- $\alpha$, IL-8 $\left(0,1,10,20\right.$, or $40 \mathrm{ng} / 2 \times 10^{7}$ cells), or sIC $(10 \% \mathrm{v} / \mathrm{v})$ for $0,2,5$, or 10 minutes at $3^{\circ} \mathrm{C}$ and for 20,40 , or 60 minutes with IL-8 (10 ng). Further experiments evaluating neutrophil shedding of AAT or FcyRIIIb included GM6001 $(20 \mu \mathrm{M})$, TAPI-1 $(10 \mu \mathrm{M})$, or exogenous AAT $(27.5 \mu \mathrm{M})$. At each time point, cells were pelleted $\left(500 \mathrm{~g}, 5\right.$ minutes, $\left.4^{\circ} \mathrm{C}\right)$ and the supernatants analyzed for the presence of released AAT or Fc $\gamma$ RIIIb.

Released AAT from neutrophils $\left(1 \times 10^{8}\right.$, approximately $550 \mu \mathrm{g}$ of total protein) was also chromatographed by gel filtration using an ÄKTApurifier 100 system (Amersham Biosciences) employing a Superose 6 column $(10 \times 300 \mathrm{~mm})$ equilibrated in PBS at a flow rate of $0.4 \mathrm{ml} / \mathrm{min}$. Ferritin (440 kDa), aldolase (158 kDa), and AAT (52 kDa) were used separately as molecular mass markers.

To biochemically evaluate the interaction of AAT with the neutrophil membrane, a purified membrane pellet was divided into 3 and either untreated, $\mathrm{NaCl}(350 \mathrm{mM})$ treated, or exposed to PI-PLC ( 2 units) for 30 minutes at $37^{\circ} \mathrm{C}$. Membranes were pelleted $\left(22,000 \mathrm{~g}, 4^{\circ} \mathrm{C}, 30\right.$ minutes) and then resuspended in $2 \times$ SDS-PAGE sample buffer and Western blotted for AAT, Fc $\gamma$ RIIIb, and p22phox.
Immunoprecipitation and protein identification using LC-MS/MS. Neutrophils were exposed to IL-8 $(10 \mathrm{ng} / \mathrm{ml})$ for 10 minutes, cells centrifuged $(500 \mathrm{~g}$, 5 minutes, $4{ }^{\circ} \mathrm{C}$ ), and resulting supernatant analyzed for the presence of AAT and associated binding partners by immunoprecipitation as previously described (29). Immunoprecipitates were subjected to denaturing SDS-PAGE under nonreducing or reducing conditions in the presence of DTT $(50 \mathrm{mM})$ and stained with Coomassie blue to visualize proteins intended for LC-MS/MS analysis. LC-MS/MS was performed on an Ultimate 3000 nanoLC system (Dionex), interfaced to an LTQ Orbitrap XL (Thermo Fisher Scientific). Protein bands were excised from the Coomassie-stained gel and destained with a solution containing $50 \%(\mathrm{v} / \mathrm{v})$ methanol and $50 \mathrm{mM} \mathrm{NH}_{4} \mathrm{HCO}_{3}$. Samples were then dehydrated by the addition of $70 \%(\mathrm{v} / \mathrm{v})$ acetonitrile $(\mathrm{ACN})$ and rehydrated in a digestion buffer containing $40 \mathrm{mM} \mathrm{NH}_{4} \mathrm{HCO}_{3}$ and $12.5 \mathrm{ng} / \mu \mathrm{l}$ trypsin (Promega, sequencing grade) at $37^{\circ} \mathrm{C}$ overnight. Peptides were extracted with $50 \%(\mathrm{v} / \mathrm{v}) \mathrm{ACN} / 0.1 \%(\mathrm{v} / \mathrm{v})$ formic acid (Fluka) dissolved in $10 \mu \mathrm{l}$ of $0.1 \%(\mathrm{v} / \mathrm{v})$ formic acid. Sample $(5 \mu \mathrm{l})$ was loaded onto a trapping column packed with C18 PepMAP100 (Dionex) at a flow rate of $20 \mu \mathrm{l} / \mathrm{min}$ in $0.1 \%$ formic acid. After 5 minutes of washing, peptides were eluted into a C18 PepMAP100 nanocolumn (15 $\mathrm{cm} \times 75 \mu \mathrm{m}$ ID, $3-\mu \mathrm{m}$ particles) (Dionex) at a flow rate of $350 \mathrm{nl} / \mathrm{min}$. Peptides were separated using the mobile phase gradient: from $5 \%$ to $50 \%(\mathrm{v} / \mathrm{v})$ of solvent $\mathrm{B}$ in 30 minutes, and from $50 \%$ to $90 \%(\mathrm{v} / \mathrm{v})$ of solvent B in 5 minutes. Solvent A was $98: 2 \mathrm{H}_{2} \mathrm{O} / \mathrm{ACN}(\mathrm{v} / \mathrm{v})$ containing $0.1 \%(\mathrm{v} / \mathrm{v})$ formic acid; solvent $\mathrm{B}$ was $2: 98 \mathrm{H}_{2} \mathrm{O} / \mathrm{ACN}(\mathrm{v} / \mathrm{v})$ containing $0.1 \%(\mathrm{v} / \mathrm{v})$ formic acid.

LC-MS/MS data were acquired in data-dependent acquisition (DDA) mode controlled by Xcalibur 2.0.7 software (Thermo Fisher Scientific). A typical DDA cycle consisted of an MS scan within $m / z 300-2,000$ performed under the target mass resolution of 60,000 (full width at half maximum), followed by MS/MS fragmentation of the 6 most intense precursor ions under normalized collision energy of $35 \%$ in the linear trap. Database searches were performed using TurboSEQUEST software (Bioworks Browser version 3.3.1) (Thermo Fisher Scientific) using the human subset from the SWISSPROT database. The following filters were applied: for charge state $1, \mathrm{X}_{\text {Corr }}>1.5$; for charge state $2, \mathrm{X}_{\text {Corr }}>2.0$; for charge state $3, \mathrm{X}_{\text {Corr }}>2.5$.

Quantification of AAT and Fc RIIIb in membrane or serum samples. For detection of the Z-form of AAT, the Wieslab $\alpha_{1}$-antitrypsin deficiency test was employed (Euro-Diagnostica), following the manufacturer's instructions as previously described $(17,18)$. Quantification of AAT on neutrophil membranes by ELISA was performed as previously described (72). The FcyRIIIb ELISA kit (R\&D Systems) was employed following the manufacturer's instructions. For the detection of FcrRIIIb-AAT complex within serum samples of normal MM, ZZ-AATD, or CF patients, $5 \mu \mathrm{g} / \mathrm{ml}$ of mouse antiFcyRIIIb (R\&D Systems) was used as a capture antibody and $50 \mathrm{ng} / \mathrm{ml}$ of polyclonal goat anti-AAT specific antibody (Abcam) as a detection antibody $(73,74)$, followed by an anti-goat IgG conjugated to HRP. Washing and blocking steps employed PBS Tween $(0.05 \%[\mathrm{v} / \mathrm{v}])$ and $1 \%(\mathrm{w} / \mathrm{v})$ BSA, respectively. Reciprocal ELISA for AAT-Fc $\gamma$ RIIIb employed goat capture antibody to AAT $(5 \mu \mathrm{g} / \mathrm{ml})$ and mouse detection antibody for Fc $\gamma$ RIIIb $(50 \mathrm{ng} / \mathrm{ml})$. Controls included all reagents except capture, detection antibody, or biotinylated secondary antibody. In additional experiments, serum $(5 \mu \mathrm{l})$ from MM or ZZ-AATD patients was applied to a radial immunodiffusion assay NOR-Partigen plate (Dade Behring) and AAT levels quantified according to the manufacturer's reference values.

ADAM-17 activity assay. Purified AAT $(0,1,2,3,5,7$, or $27.5 \mu \mathrm{M})$ was incubated with Rh ADAM-17 for 5 minutes at room temperature and ADAM-17 activity assayed using the fluorogenic peptide substrate MCAProLeuAlaGlnAlaValDPAArgSerSerSerArgNH according to the manufacturer's instructions (R\&D Systems). Experiments were repeated in the presence of oxidized AAT, polymerized AAT, or the C-36 fragment (amino acid sequence 358-396) of AAT (Saveen Werner). Oxidized AAT was prepared as 
previously described (75). To prepare a polymer sample of monomeric (native) AAT, the native sample $(1 \mathrm{mg} / \mathrm{ml})$ was heated at $55^{\circ} \mathrm{C}$ for 16 hours as previously described (74). Studies have shown no major difference between polymers of AAT generated by this method compared with ZZ-AAT (74, 76-79). GraphPad Prism version 4.03 was employed to calculate $K_{i}$ values, with global curve fit performed finding the single best-fit estimate. Nonlinear regression analysis was employed to determine AAT and ADAM-17 association $\left(K_{\text {ass }}\right)$ and dissociation rate constant as previously described (80).

Protein binding assays. AAT-NE complexes were formed as previously described (81). Reactions were subjected to Western blot analysis for AAT $(52 \mathrm{kDa})$ or AAT-NE complexes $(80 \mathrm{kDa})$. The method employed for detection of binding of IL-8 to plasma purified AAT $(27.5 \mu \mathrm{M})$, HSA $(27.5 \mu \mathrm{M})$, recombinant nonglycosylated AAT (Prospec), or recombinant CXCR1 (Abnova) and the method employed for detection of the AAT-Fc $\gamma$ RIIIb were as previously described (26). For example, wells from Nunc 96-well microtiter plates were coated with $27.5 \mu \mathrm{M}$ AAT in Voller's buffer $(15 \mathrm{mM}$ $\mathrm{Na}_{2} \mathrm{CO}_{3}$ and $\left.35 \mathrm{mM} \mathrm{NaHCO}_{3}, \mathrm{pH} 9.3\right)$ at $4{ }^{\circ} \mathrm{C}$ overnight and exposed to $\mathrm{Rh}$ Fc $\gamma$ RIIIb or Fc $\gamma$ RIIa (R\&D Systems) $(0,1,5$, or $10 \mu \mathrm{g}$ ) prepared in HEPES buffer (10 mM HEPES, pH 7.4, $150 \mathrm{mM} \mathrm{NaCl}, 3.4 \mathrm{mM}$ EDTA, and 0.05\% [v/v] Tween 20) for 1 hour at $37^{\circ} \mathrm{C}$. Binding to AAT was determined by probing the wells with a monoclonal IgG antibody to either Fc $\gamma$ RIIIb or Fc $\gamma$ RIIa (R\&D Systems), followed by HRP anti-mouse IgG in HEPES buffer and $1 \%(\mathrm{w} / \mathrm{v})$ BSA. The plates were washed 3 times with HEPES buffer, peroxidase activity was measured by the addition of ABTS, and the absorbance was measured at $405 \mathrm{~nm}$.

For detection of the AAT-ADAM-17 complex, AAT-coated plates were exposed to ADAM-17 (250 ng) for 1 hour at $37^{\circ} \mathrm{C}$ or ADAM-17 preincubated with equimolar concentration of the C-36 peptide fragment, polymerized AAT, or native AAT for 30 minutes. Binding of ADAM-17 was quantified using a monoclonal IgG antibody to ADAM-17 (Immunex Corp.), followed by monoclonal HRP-anti-mouse IgG. The controls for binding assays included the AAT-coated wells containing all reagents except primary and/or HRP secondary antibody and the AAT-coated wells incubated only with HRP conjugate.

Statistics. Results are expressed as mean \pm SEM. The data were analyzed with GraphPad Prism version 4.03 for Windows (GraphPad Software). The Mann-Whitney $U$ test or Kolmogorov-Smirnov 2-sample test was employed to identify significant differences. A $P$ value less than 0.05 was deemed significantly different.

\section{Acknowledgments}

We thank B.J. Harvey, W. Thomas, and O. McCabe, RCSI Molecular Medicine Laboratories, for providing support on the Zeiss LSM710 confocal immunofluorescence microscope purchased through the National Biophotonics Imaging Platform funding; the Children's Research Centre, Crumlin Hospital, Dublin, for FPLC facilities; G. Mullins and C. O'Connor, Alpha One Foundation (Ireland) for collection of AATD patient samples; E. Hayes for collection of CF patient serum samples; R. O'Kennedy and B. Byrne, Applied Biochemistry Group, School of Biotechnology, Dublin City University, for protein binding studies. We thank all AATD and CF patients who participated in this study. This work was supported by the Alpha-1 Foundation (U.S.), the Medical Research Charities Group/Health Research Board, and the Programme for Research in Third-Level Institutes (PRTLI) administered by the Higher Education Authority.

Received for publication September 17, 2009, and accepted in revised form September 15, 2010.

Address correspondence to: Emer P. Reeves, Respiratory Research Division, Department of Medicine, Royal College of Surgeons in Ireland, Education and Research Centre, Beaumont Hospital, Dublin 9, Ireland. Phone: 353.1.8093877; Fax: 353.1.8093808; E-mail: emerreeves@rcsi.ie.
1. Nita IM, Serapinas D, Janciauskiene SM. Alpha1Antitrypsin regulates $\mathrm{CD} 14$ expression and soluble CD14 levels in human monocytes in vitro. Int J Biochem Cell Biol. 2007;39(6):1165-1176.

2. Subramaniyam D, et al. TNF-alpha-induced self expression in human lung endothelial cells is inhibited by native and oxidized alpha1-antitrypsin. Int J Biochem Cell Biol. 2008;40(2):258-271.

3. Janciauskiene S, Larsson S, Larsson P, Virtala R, Jansson L, Stevens T. Inhibition of lipopolysaccharide-mediated human monocyte activation, in vitro, by alpha1-antitrypsin. Biochem Biophys Res Commun. 2004;321(3):592-600.

4. Stockley RA, Shaw J, Afford SC, Morrison HM, Burnett D. Effect of alpha-1-proteinase inhibitor on neutrophil chemotaxis. Am J Respir Cell Mol Biol. 1990;2(2):163-170.

5. Petrache I, et al. Alpha-1 antitrypsin inhibits caspase-3 activity, preventing lung endothelial cell apoptosis. Am J Pathol. 2006;169(4):1155-1166.

6. Rooney CP, Taggart C, Coakley R, McElvaney NG, O'Neill SJ. Anti-proteinase 3 antibody activation of neutrophils can be inhibited by alpha1-antitrypsin. Am J Respir Cell Mol Biol. 2001;24(6):747-754.

7. Carlson JA, et al. Accumulation of PiZ alpha 1antitrypsin causes liver damage in transgenic mice. J Clin Invest. 1989;83(4):1183-1190.

8. Perlmutter DH, Schlesinger MJ, Pierce JA, Punsal PI, Schwartz AL. Synthesis of stress proteins is increased in individuals with homozygous PiZZ alpha 1-antitrypsin deficiency and liver disease. J Clin Invest. 1989;84(5):1555-1561.

9. Miller SD, et al. Tauroursodeoxycholic acid inhibits apoptosis induced by $Z$ alpha- 1 antitrypsin via inhibition of Bad. Hepatology. 2007;46(2):496-503.
10. McElvaney NG. Proteases and lung injury. In: Crystal RG, Weibel ER, Barnes PJ, eds. The Lung: Scientific Foundations. New York, New York, USA: Raven Press, Inc.; 1997:2205-2219.

11. Taggart CC, Greene CM, Carroll TP, O’Neill SJ, McElvaney NG. Elastolytic proteases: inflammation resolution and dysregulation in chronic infective lung disease. Am J Respir Crit Care Med. 2005; 171(10):1070-1076.

12. Wewers MD, et al. Replacement therapy for alpha 1antitrypsin deficiency associated with emphysema. N Engl J Med. 1987;316(17):1055-1062.

13. Rouhani F, Paone G, Smith NK, Krein P, Barnes P, Brantly ML. Lung neutrophil burden correlates with increased pro-inflammatory cytokines and decreased lung function in individuals with alpha(1)-antitrypsin deficiency. Chest. 2000;117(5 suppl 1):250S-251S.

14. Malerba $M$, et al. Neutrophilic inflammation and IL-8 levels in induced sputum of alpha-1-antitrypsin PiMZ subjects. Thorax. 2006;61(2):129-133.

15. du Bois RM, et al. Human neutrophils express the alpha 1-antitrypsin gene and produce alpha 1-antitrypsin. Blood. 1991;77(12):2724-2730.

16. Zerimech F, et al. Evaluation of a new Sebia isolectrofocusing kit for $\mathrm{a}_{1}$-antitrypsin phenotyping with the Hydrasys System. Clin Chem Lab Med. 2008; 46(2):260-263.

17. Gershagen S, Janciauskiene S. ELISA for specific detection of PiZ-related alpha(1)-antitrypsin deficiency. Clin Chem. 2004;50(12):2407-2410.

18. Kelly E, Greene CM, Carroll TP, McElvaney NG, O'Neill SJ. Selenoprotein S/SEPS1 modifies endoplasmic reticulum stress in $Z$ variant \{alpha\}1-antitrypsin deficiency. J Biol Chem. 2009;
284(25):16891-16897.

19. Middelhoven PJ, Ager A, Roos D, Verhoeven AJ. Involvement of a metalloprotease in the shedding of human neutrophil Fc gammaRIIIB. FEBS Lett. 1997;414(1):14-18.

20. Coxon A, et al. Fc gamma RIII mediates neutrophil recruitment to immune complexes. a mechanism for neutrophil accumulation in immune-mediated inflammation. Immunity. 2001;14(6):693-704.

21. Kew RR, Grimaldi CM, Furie MB, Fleit HB. Human neutrophil Fc gamma RIIIB and formyl peptide receptors are functionally linked during formyl-methionyl-leucyl-phenylalanine-induced chemotaxis. J Immunol. 1992;149(3):989-997.

22. Rhein LM, Perkins M, Gerard NP, Gerard C. FcgammaRIII is protective against Pseudomonas aeruginosa pneumonia. Am J Respir Cell Mol Biol. 2008; 38(4):401-406.

23. Schaff U, Mattila PE, Simon SI, Walcheck B. Neutrophil adhesion to E-selectin under shear promotes the redistribution and co-clustering of ADAM-17 and its proteolytic substrate L-selectin. J Leukoc Biol. 2008;83(1):99-105.

24. Kuschert GS, et al. Glycosaminoglycans interact selectively with chemokines and modulate receptor binding and cellular responses. Biochemistry. 1999;38(39):12959-12968.

25. Marshall LJ, et al. Plasminogen activator inhibitor-1 supports IL-8-mediated neutrophil transendothelial migration by inhibition of the constitutive shedding of endothelial IL-8/heparan sulfate/syndecan-1 complexes. J Immunol. 2003;171(4):2057-2065.

26 . Reeves EP, et al. IL-8 dictates glycosaminoglycan binding and stability of IL-18 in cystic fibrosis. JImmunol. 2010;184(3):1642-1652. 
27. Lane HC, Anand AR, Ganju RK. Cbl and Akt regulate CXCL8-induced and CXCR1- and CXCR2-mediated chemotaxis. Int Immunol. 2006; 18(8):1315-1325.

28. Schaff UY, Yamayoshi I, Tse T, Griffin D, Kibathi L, Simon SI. Calcium flux in neutrophils synchronizes beta 2 integrin adhesive and signaling events that guide inflammatory recruitment. Ann Biomed Eng. 2008;36(4):632-646.

29. Grogan A, et al. Cytosolic phox proteins interact with and regulate the assembly of coronin in neutrophils. J Cell Sci. 1997;110(pt 24):3071-3081.

30. Westlin WF, Kiely JM, Gimbrone MA Jr. Interleukin- 8 induces changes in human neutrophil actin conformation and distribution: relationship to inhibition of adhesion to cytokine-activated endothelium. J Lenkoc Biol. 1992;52(1):43-51.

31. Bucurenci N, Blake DR, Chidwick K, Winyard PG. Inhibition of neutrophil superoxide production by human plasma alpha 1-antitrypsin. FEBS Lett. 1992;300(1):21-24.

32. Janciauskiene SM, Nita IM, Stevens T. Alpha1antitrypsin, old dog, new tricks. Alpha1-antitrypsin exerts in vitro anti-inflammatory activity in human monocytes by elevating cAMP. J Biol Chem. 2007;282(12):8573-8582

33. Lu Y, et al. Alpha1-antitrypsin gene therapy modulates cellular immunity and efficiently prevents type 1 diabetes in nonobese diabetic mice. Hum Gene Ther. 2006;17(6):625-634.

34. Daemen MA, et al. Functional protection by acute phase proteins alpha(1)-acid glycoprotein and alpha(1)-antitrypsin against ischemia/reperfusion injury by preventing apoptosis and inflammation. Circulation. 2000;102(12):1420-1426.

35 . Bylund J, et al. Cytochalasin B triggers a novel pertussis toxin sensitive pathway in TNF-alpha primed neutrophils. BMC Cell Biol. 2004;5:21.

36. Edwards SW. Biochemistry And Physiology Of The New trophil. Cambridge, United Kingdom: Cambridge University Press; 1994.

37. Woolhouse IS, Bayley DL, Lalor P, Adams DH, Stockley RA. Endothelial interactions of neutrophils under flow in chronic obstructive pulmonary disease. Eur Respir J. 2005;25(4):612-617.

38. Proudfoot AE, et al. Glycosaminoglycan binding and oligomerization are essential for the in vivo activity of certain chemokines. Proc Natl Acad Sci U S A. 2003;100(4):1885-1890.

39. Solic N, Wilson J, Wilson SJ, Shute JK. Endothelial activation and increased heparan sulfate expression in cystic fibrosis. Am J Respir Crit Care Med. 2005;172(7):892-898.

40. Schumacher C, Clark-Lewis I, Baggiolini M, Moser B. High- and low-affinity binding of GRO alpha and neutrophil-activating peptide 2 to interleukin 8 receptors on human neutrophils. Proc Natl Acad Sci U S A. 1992;89(21):10542-10546.

41. Wuyts A, Proost P, Lenaerts JP, Ben-Baruch A, Van Damme J, Wang JM. Differential usage of the CXC chemokine receptors 1 and 2 by interleukin- 8 , granulocyte chemotactic protein-2 and epithelialcell-derived neutrophil attractant-78. Eur JBiochem. 1998;255(1):67-73

42. Kurdowska A, et al. Specific binding of IL-8 to rabbit alpha-macroglobulin modulates IL-8 function in the lung. Inflamm Res. 2000;49(11):591-599.

43. Lucattelli $\mathrm{M}$, et al. Is neutrophil elastase the missing link between emphysema and fibrosis? Evidence from two mouse models. Respir Res. 2005;6:83.

44. Travis J, et al. Isolation and properties of recombinant DNA produced variants of human alpha 1-proteinase inhibitor. J Biol Chem. 1985;260(7):4384-4389.

45. Wencker M, Fuhrmann B, Banik N, Konietzko N Longitudinal follow-up of patients with alpha(1)protease inhibitor deficiency before and during therapy with IV alpha(1)-protease inhibitor. Chest.
2001;119(3):737-744.

46. Lieberman J. Augmentation therapy reduces frequency of lung infections in antitrypsin deficiency: a new hypothesis with supporting data. Chest. 2000;118(5):1480-1485.

47. Dirksen A, et al. A randomized clinical trial of alpha(1)-antitrypsin augmentation therapy. $A m J$ Respir Crit Care Med. 1999;160(5 pt 1):1468-1472.

48. Pujazon MC, Carles P. [Augmentation therapy with alpha-1 antitrypsin:20 year- follow-up of a deficient patient]. Rev Mal Respir. 2008;25(9):1136-1141.

49. Paakko P, Kirby M, du Bois RM, Gillissen A, Ferrans VJ, Crystal RG. Activated neutrophils secrete stored alpha 1-antitrypsin. Am J Respir Crit Care Med. 1996;154(6 pt 1):1829-1833.

50. Kolarich D, Weber A, Turecek PL, Schwarz HP, Altmann F. Comprehensive glyco-proteomic analysis of human alpha1-antitrypsin and its charge isoforms. Proteomics. 2006;6(11):3369-3380.

51. Campbell EJ, Owen CA. The sulfate groups of chondroitin sulfate- and heparan sulfate-containing proteoglycans in neutrophil plasma membranes are novel binding sites for human leukocyte elastase and cathepsin G. J Biol Chem. 2007;282(19):14645-14654.

52. Meknache N, Jonsson F, Laurent J, Guinnepain MT, Daeron M. Human basophils express the glycosylphosphatidylinositol-anchored low-affinity IgG receptor FcgammaRIIIB (CD16B). J Immunol. 2009;182(4):2542-2550

53. Fernandes MJ, et al. CD16b associates with highdensity, detergent-resistant membranes in human neutrophils. Biochem J. 2006;393(pt 1):351-359.

54. Edberg JC, Kimberly RP. Modulation of Fc gamma and complement receptor function by the glycosylphosphatidylinositol-anchored form of Fc gamma RIII. J Immunol. 1994;152(12):5826-5835.

55. Huizinga TW, et al. The PI-linked receptor FcRIII is released on stimulation of neutrophils. Nature. 1988;333(6174):667-669.

56. Middelhoven PJ, Van Buul JD, Hordijk PL, Roos D Different proteolytic mechanisms involved in $\mathrm{Fc}$ gamma RIIIb shedding from human neutrophils. Clin Exp Immunol. 2001;125(1):169-175.

57. Galon J, et al. Identification of the cleavage site involved in production of plasma soluble $\mathrm{FC}$ gamma receptor type III (CD16). Eur I Immunol. 1998;28(7):2101-2107.

58. Long C, Wang Y, Herrera AH, Horiuchi Dagger K, Walcheck B. In vivo role of leukocyte ADAM-17 in the inflammatory and host responses during E. coli-mediated peritonitis. J Leukoc Biol. 2010; 87:1097-1101

59. Brynskov J, et al. Tumour necrosis factor alpha converting enzyme (TACE) activity in the colonic mucosa of patients with inflammatory bowel disease. Gut. 2002;51(1):37-43.

60. Churg A, et al. Alpha-1-antitrypsin and a broad spectrum metalloprotease inhibitor, RS113456, have similar acute anti-inflammatory effects. $L a b$ Invest. 2001;81(8):1119-1131

61. Churg A, Wang RD, Xie C, Wright JL. Alpha-1Antitrypsin ameliorates cigarette smoke-induced emphysema in the mouse. Am J Respir Crit Care Med. 2003;168(2):199-207.

62. Lewis EC, et al. Alpha1-Antitrypsin monotherapy induces immune tolerance during islet allograft transplantation in mice. Proc Natl Acad Sci U S A. 2008;105(42):16236-16241.

63. Reeves EP, et al. Killing activity of neutrophils is mediated through activation of proteases by $\mathrm{K}+$ flux. Nature. 2002;416(6878):291-297.

64. Watson F, Gasmi L, Edwards SW. Stimulation of intracellular $\mathrm{Ca} 2+$ levels in human neutrophils by soluble immune complexes. Functional activation of FcgammaRIIIb during priming.J Biol Chem. 1997:272(29):17944-17951.
65. Weathington NM, et al. A novel peptide CXCR ligand derived from extracellular matrix degradation during airway inflammation. Nat Med. 2006;12(3):317-323.

66. Marx N, et al. C-peptide colocalizes with macrophages in early arteriosclerotic lesions of diabetic subjects and induces monocyte chemotaxis in vitro. Arterioscler Thromb Vasc Biol. 2004;24(3):540-545.

67. Guichard C, et al. Interleukin-8-induced priming of neutrophil oxidative burst requires sequential recruitment of NADPH oxidase components into lipid rafts. J Biol Chem. 2005;280(44):37021-37032.

68. Dahlgren C, Karlsson A, Sendo F. Neutrophil secretory vesicles are the intracellular reservoir for GPI80 , a protein with adhesion-regulating potential. J Leukoc Biol. 2001;69(1):57-62.

69. Morgan CP, Sengelov H, Whatmore J, Borregaard $\mathrm{N}$, Cockcroft S. ADP-ribosylation-factor-regulated phospholipase D activity localizes to secretory vesicles and mobilizes to the plasma membrane following $\mathrm{N}$-formylmethionyl-leucyl-phenylalanine stimulation of human neutrophils. Biochem J. 1997;325(pt 3):581-585

70. Song KS, Li S, Okamoto T, Quilliam LA, Sargiacomo M, Lisanti MP. Co-purification and direct interaction of Ras with caveolin, an integral membrane protein of caveolae microdomains. Detergent-free purification of caveolae microdomains. J Biol Chem. 1996;271(16):9690-9697.

71. Jayachandran R, et al. Survival of mycobacteria in macrophages is mediated by coronin 1-dependent activation of calcineurin. Cell. 2007;130(1):37-50.

72. Lawless MW, Greene CM, Mulgrew A, Taggart CC, O'Neill SJ, McElvaney NG. Activation of endoplasmic reticulum-specific stress responses associated with the conformational disease $Z$ alpha 1-antitrypsin deficiency. J Immunol. 2004;172(9):5722-5726.

73. Hinson ER, Cresswell P. The N-terminal amphipathic alpha-helix of viperin mediates localization to the cytosolic face of the endoplasmic reticulum and inhibits protein secretion. J Biol Chem. 2009; 284(7):4705-4712.

74. Mahadeva R, et al. Polymers of $Z$ alpha1-antitrypsin co-localize with neutrophils in emphysematous alveoli and are chemotactic in vivo. Am J Pathol.2005; 166(2):377-386.

75. Li Z, Alam S, Wang J, Sandstrom CS, Janciauskiene S, Mahadeva R. Oxidized \{alpha\}1-antitrypsin stimulates the release of monocyte chemotactic protein-1 from lung epithelial cells: potential role in emphysema. Am J Physiol Lung Cell Mol Physiol. 2009;297(2):L388-400.

76. Lomas DA, Evans DL, Finch JT, Carrell RW. The mechanism of $Z$ alpha 1-antitrypsin accumulation in the liver. Nature. 1992;357(6379):605-607.

77. Lomas DA, Mahadeva R. Alpha1-antitrypsin polymerization and the serpinopathies: pathobiology and prospects for therapy. J Clin Invest. 2002;110(11):1585-1590

78. Mahadeva R, Dafforn TR, Carrell RW, Lomas DA. 6-mer peptide selectively anneals to a pathogenic serpin conformation and blocks polymerization. Implications for the prevention of $\mathrm{Z}$ alpha(1)-antitrypsin-related cirrhosis. J Biol Chem. 2002;277(9):6771-6774

79. Sivasothy P, Dafforn TR, Gettins PG, Lomas DA. Pathogenic alpha 1-antitrypsin polymers are formed by reactive loop-beta-sheet A linkage. J Biol Chem. 2000;275(43):33663-33668.

80. Beatty K, Bieth J, Travis J. Kinetics of association of serine proteinases with native and oxidized alpha-1proteinase inhibitor and alpha-1-antichymotrypsin. J Biol Chem. 1980;255(9):3931-3934.

81. Taggart $\mathrm{C}$, et al. Oxidation of either methionine 351 or methionine 358 in alpha 1-antitrypsin causes loss of anti-neutrophil elastase activity. J Biol Chem. 2000;275(35):27258-27265. 